\title{
Insights into the controls on metabolite distributions along a latitudinal transect of the western Atlantic Ocean
}

Winifred M. Johnson ${ }^{1 *}$, Melissa C. Kido Soule ${ }^{2}$, Krista Longnecker ${ }^{2}$, Maya P. Bhatia ${ }^{3}$, Steven J. Hallam ${ }^{4,5,6,7,8}$, Michael W. Lomas ${ }^{9}$, Elizabeth B. Kujawinski ${ }^{2}$

1- MIT/WHOI Joint Program in Oceanography/Applied Ocean Sciences and

Engineering, Department of Marine Chemistry \& Geochemistry, Woods Hole

Oceanographic Institution, Woods Hole, MA 02543, USA

2- Department of Marine Chemistry \& Geochemistry, Woods Hole Oceanographic Institution, Woods Hole, MA 02543, USA

3- Department of Earth and Atmospheric Sciences, University of Alberta, Edmonton, Alberta, T6G 2E3, Canada

4- Department of Microbiology \& Immunology, University of British Columbia, Vancouver, BC V6T 1Z1, Canada.

5- Graduate Program in Bioinformatics, University of British Columbia, Vancouver, BC V6T 1Z4, Canada.

6- Genome Science and Technology Program, University of British Columbia, 2329

West Mall, Vancouver, BC V6T 1Z4, Canada.

7- Life Sciences Institute, University of British Columbia, Vancouver, BC V6T 1Z3, Canada.

8- ECOSCOPE Training Program, University of British Columbia, Vancouver, BC V6T 1Z3, Canada.

9- Bigelow Laboratory for Ocean Sciences, East Boothbay, ME 04544, USA

*- corresponding author:

Department of Chemistry and Biochemistry

University of North Carolina Wilmington

601 S College Rd

Wilmington, NC 28403

Phone: 910-962-2902

Email: johnsonwm@uncw.edu 


\section{Abstract:}

44

45 Metabolites, or the small organic molecules that are synthesized by cells during

46 metabolism, comprise a complex and dynamic pool of carbon in the ocean. They are an

47 essential form of information, linking genotype to phenotype at the individual, population

48 and community levels of biological organization. Characterizing metabolite distributions

49 inside microbial cells and dissolved in seawater is essential to understanding the controls

50 on their production and fate, as well as their roles in shaping marine microbial food webs.

51 Here, we apply a targeted metabolomics method to quantify particulate and dissolved

52 distributions of a suite of biologically relevant metabolites including vitamins, amino

53 acids, nucleic acids, osmolytes, and intermediates in biosynthetic pathways along a

54 latitudinal transect in the western Atlantic Ocean. We find that, in the euphotic zone,

55 most particulate or intracellular metabolites positively co-vary with the most abundant

56 microbial taxa. In contrast, dissolved metabolites exhibited greater variability with

57 differences in distribution between ocean regions. Although fewer particulate metabolites

58 were detected below the euphotic zone, molecules identified in the deep ocean may be

59 linked to preservation of organic matter or adaptive physiological strategies of deep-sea

60 microbes. Based on the identified metabolite distributions, we propose relationships

61 between certain metabolites and microbial populations, and find that dissolved metabolite

62 distributions are not directly related to their particulate abundances. 


\section{Introduction}

65 Marine organic matter is a complex component of the global carbon cycle due to its

66 molecular diversity across particulate and dissolved phases. Cycling of this organic

67 matter is largely controlled by the relationship between microbial metabolism and

68 dissolved organic carbon (DOC) as marine microbes produce, consume, and influence the

69 composition of DOC. About $50 \%$ of the organic matter fixed by phytoplankton passes

70 through the marine DOC pool (Ducklow 1999), which is a carbon reservoir similar in

71 size to that of carbon dioxide in the atmosphere (Hansell et al. 2009). Within the marine

72 DOC pool, organic molecules are cycled on timescales ranging from minutes to

73 thousands of years (reviewed by Carlson and Hansell 2015).

74 To adequately understand the factors that control production and removal of organic

75 matter, molecular-level characterization of this material is needed. Compositional studies

76 of organic matter have predominantly focused on compound classes. While a much

77 smaller portion of the organic matter reservoir in the ocean, suspended particulate organic

78 matter can be a source of dissolved organic matter through processes like cell death,

79 grazing, and viral lysis (Carlson and Hansell 2015). These particles are composed of

80 biologically-derived organic matter in the form of living cells and detritus including

81 carbohydrates, amino acids, lipids, nucleic acids, and additional small molecules required

82 for metabolism and secondary metabolites (e.g. Biersmith and Benner 1998; Sheridan et

83 al. 2002; Kawasaki et al. 2011; Johnson et al. 2020).

84 Studies of molecular classes have determined that a large portion of high-molecular

85 weight DOC is comprised of carbohydrates (Aluwihare et al. 1997) as well as carboxyl-

86 rich aliphatic material (Hertkorn et al. 2006). Hydrolysable and free individual amino 
87 acids make up a smaller portion of organic carbon (McCarthy et al. 1996; Kaiser and

88 Benner 2009). An additional group of molecules in DOC, identified with ultrahigh-

89 resolution mass spectrometry of solid phase-extracted DOC, includes compounds with

90 molecular formulas that do not match common biochemical compound classes, likely

91 derived from pyro- and petrogenic sources (Dittmar and Koch 2006).

92 Metabolites, including free amino acids and monomeric sugars as well as vitamins

93 and metabolic intermediates, while comprising a relative minor proportion of DOC in the

94 ocean, play essential roles as the currencies in marine microbial interactions, transferring

95 energy, cellular components, and information among microbial neighbors (Kujawinski

96 2011; Moran et al. 2016). By simultaneously measuring a suite of these molecules, we

97 can trace the relationships between their distributions in particulate and dissolved phases,

98 and hypothesize about the controls on their production, removal, and roles in microbial

99 communities.

100 Metabolites, or small biomolecules, are defined as the products of all cellular

101 regulation (Fiehn 2002). Due to the sensitivity of metabolite concentrations to both

102 genetic and environmental factors, the metabolite profile of an organism can be

103 considered an aspect of its phenotype. Intracellular or particulate metabolite

104 concentrations respond to physical, chemical, and biological environmental cues

105 including nutrient limitation (Brauer et al. 2006; Kujawinski et al. 2017), salinity (Gebser

106 and Pohnert 2013), temperature (Thompson et al. 1992), oxidative stress (Lesser 2006),

107 grazing (Pohnert 2000; Longnecker and Kujawinski 2020), viral lysis (Ankrah et al.

108 2014), available carbon substrates (Johnson et al. 2016), and the presence of

109 infochemicals (Seyedsayamdost et al. 2011). For example, in response to infection by a 
110 phage, a marine bacterium had elevated intracellular concentrations of some amino acids

111 and sugars (Ankrah et al. 2014). Thus, probing particulate and dissolved metabolite

112 concentrations within the contexts of environmental cues and microbe-microbe

113 interactions may elucidate phenotypic variations in microbes under environmental

114 stressors, and thus facilitate understanding of exuded or released microbial organic matter

115 under various conditions (Kujawinski 2011; Moran et al. 2016).

116 Dissolved metabolites mediate interactions among marine organisms. This

117 encompasses both the transfer of organic substrates through the food web as well as the

118 subtle but often significant role of infochemicals in influencing an organism's phenotype

119 (e.g. Paul et al. 2012; Barak-Gavish et al. 2018). Heterotrophic microbes catabolize many

120 metabolite types produced by autotrophic microbes. For example, sugars fuel a dominant

121 component of the marine food web, supporting aerobic respiration (Søndergaard et al.

122 2000). A common algal metabolite, dimethylsulfoniopropionate (DMSP), is used for both

123 energy and reduced sulfur (Kiene et al. 2000). Amino acids also move through the food

124 web, providing both fixed nitrogen and essential cellular building blocks (Rich et al.

125 1997). In addition to the autotrophic production of organic substrates for heterotrophic

126 remineralization, some metabolites fulfill requirements in sympatric community

127 members. For instance, certain species of phytoplankton require vitamins that they cannot

128 synthesize de novo, such as vitamin $\mathrm{B}_{12}$ or biotin; these vitamins are produced by

129 heterotrophic bacteria and sustain phytoplankton growth (reviewed by Croft et al. 2006).

130 Some heterotrophic bacteria also have specific substrate requirements, such as a SAR11

131 isolate that requires an exogenous source of a thiamin precursor (Carini et al. 2014).

132 These physiological demands have been studied on a case-by-case basis using field and 
133 lab experiments coupled with genomic information. However, our knowledge of the

134 distributions of many of these metabolites in the ocean is limited or non-existent, thus

135 inhibiting our ability to predict the impact of these requirements on microbial

136 communities in the field.

137 To quantify a suite of structurally diverse metabolites, we use a liquid

138 chromatography-tandem mass spectrometry-based metabolomics approach (Kido Soule

139 et al. 2015). In this targeted metabolomics method, pure standards of each metabolite of

140 interest are used to identify and quantify that metabolite in seawater. In this study,

141 seawater samples encompassed a variety of ocean regions, between the latitudes of $55^{\circ} \mathrm{N}$

142 and $38^{\circ} \mathrm{S}$ in the western Atlantic and from depths between $5 \mathrm{~m}$ and $\sim 5500 \mathrm{~m}$. Our method

143 detected 27 particulate metabolites and 18 dissolved metabolites, including amino acids,

144 vitamins, nucleic acids, osmolytes, and a variety of metabolic intermediates from both

145 primary metabolism and biosynthetic pathways. Many of these metabolites were selected

146 because they are essential for most organisms, while others were identified in laboratory

147 experiments as being responsive to environmental differences or being specific to certain

148 groups of organisms. Some of these metabolites have been measured previously in the

149 ocean, allowing us to compare our measurements to literature values while other

150 metabolites have never been measured, to our knowledge, in the ocean.

151 The goal of this study is to quantify the distribution of the core set of metabolites in

152 our method along latitudinal and depth gradients in the Atlantic Ocean. In particular, the

153 identification of metabolites whose distributions are independent of microbial biomass

154 may lead to discovery of other environmental controls on the production or degradation

155 of those molecules in certain ocean regions. As the majority of the metabolites analyzed 
156 are essential components of metabolism, starting from the null hypothesis that each

157 metabolite is present in the same abundance inside a cell anywhere in the ocean and that

158 its release into, and uptake from, the dissolved pool of metabolites is driven only by the

159 number of cells present, particulate and dissolved metabolite distributions should co-vary

160 with biomass. However, we find that this is not the case, and metabolite concentrations

161 correlate to a variety of factors. We distill our results within the following three contexts:

162 1) particulate metabolite distributions that are correlated to abundant microbial

163 community members, 2) dissolved metabolite distributions that vary across ocean regions

164 and 3) particulate metabolite distributions in the euphotic zone versus the deep ocean.

\section{Materials and methods}

\section{Materials}

168 We obtained all metabolite standards from Sigma-Aldrich at the highest purity

169 available with the exception of dimethylsulfoniopropionate (DMSP), which we purchased

170 from Research Plus, Inc. We purchased hydrochloric acid (trace metal grade), acetonitrile

171 (Optima grade), and methanol (Optima grade) from Fisher Scientific. We obtained formic

172 acid (LC-MS grade) from Fluka Analytical. We purchased glutamic acid-d $\mathrm{d}_{3}$ from

173 Cambridge Isotopes, 4-hydroxybenzoic acid-d $\mathrm{d}_{4}$ from CDN Isotopes, and sodium

174 taurocholate- $\mathrm{d}_{5}$ from Toronto Research Chemicals through Fisher Scientific. We used

175 water purified by a Milli-Q system (Millipore; resistivity $18.2 \mathrm{M} \Omega \bullet \mathrm{cm} @ 25^{\circ} \mathrm{C}$, TOC <

$1761 \mu \mathrm{M}$ ) for all cleaning, eluents, and solutions. We combusted all glassware and GF/F

177 filters in an oven at $460^{\circ} \mathrm{C}$ for at least $5 \mathrm{~h}$. We acid-washed and autoclaved all plasticware 
178 before use. We flushed the filter holders and tubing for shipboard filtration with $10 \% \mathrm{HCl}$

179 and then Milli-Q water between each sample.

180

\section{$181 \quad$ Field Sites}

182 We collected samples over the course of two cruises in 2013. Cruise KN210-04

183 (Deep DOM) took place in the western tropical Atlantic from 25 March - 9 May (austral

184 fall), transiting from Montevideo, Uruguay to Bridgetown, Barbados. In the north

185 Atlantic, we collected samples on the second leg of cruise AE1319 transiting from

186 Boothbay Harbor, Maine U.S.A. to Bermuda via the Labrador Sea from 20 August - 11

187 September (boreal late summer - early fall). On KN210-04 we collected samples at

188 depths including $5 \mathrm{~m}$ (referred to as the surface), the deep chlorophyll maximum (DCM)

189 determined by fluorescence, $250 \mathrm{~m}$, Antarctic Intermediate Water (AAIW, 1000 m),

190 North Atlantic Deep Water (NADW, 2500 m), and Antarctic Bottom Water (AABW,

$191 \sim 5000 \mathrm{~m})$. On cruise AE1319 we collected samples at $5 \mathrm{~m}$, the DCM, Eighteen Degree

192 Mode Water ( 350 m, where present), 1000 m, and $3000 \mathrm{~m}$. See Table $\mathrm{S} 1$ for mixed

193 layer, euphotic zone, and DCM depths.

\section{Total organic carbon (TOC)}

196 We collected $40 \mathrm{~mL}$ samples of unfiltered seawater in combusted glass EPA vials.

197 We acidified the water samples to $\mathrm{pH}$ 2-3 with concentrated hydrochloric acid and stored

198 them at $4{ }^{\circ} \mathrm{C}$ until analysis. We analyzed the samples on a Shimadzu TOC-VCSH total

199 organic carbon analyzer coupled to a TNM-1 analyzer. We ran Milli-Q water blanks and

200 standard curves of potassium hydrogen phthalate and potassium nitrate throughout 
201 analysis and made comparisons daily to standards from Prof. D. Hansell (University of

202 Miami).

203

204 Temperature, salinity, photosynthetically active radiation (PAR), chlorophyll $a$, and

205 cell counts

206 The R/V Knorr (KN210-04) was equipped with a SBE9+ CTD with a depth limit of

$2076000 \mathrm{~m}$. We used a SBE3T/SBE4C sensor system to measure temperature and

208 conductivity, a Wet Labs FLNTURTD combination fluorometer and turbidity sensor to

209 detect fluorescence, and a Biospherical QSP-200L underwater PAR sensor. The R/V

210 Atlantic Explorer (AE1319) had a SBE 9/11 Plus CTD with a depth limit of 6800 m with

211 a SBE 3+ temperature sensor, a SBE 4C conductivity sensor, and a Biospherical QSP-

2122350 Scalar PAR sensor. We used a Chelsea Aquatracka II to measure fluorescence. We

213 calibrated fluorescence data from both cruises with direct chlorophyll $a$ measurements

214 (according to methods from Arar \& Collins (1997) on KN210-04; according to methods

215 from Yentsch and Menzel (1963) on AE1319). Prokaryotic cell counts for cruise KN210-

21604 were based on epifluorescence microscopy of cells stained with SYBR Green I stain

217 and captured on a $0.02 \mu \mathrm{m}$ Anodisc filter (for a complete method see Noble and Fuhrman

218 1998).

219

220 Shipboard sample processing

221 We collected water (4 L) directly from Niskin bottles into polytetrafluoroethylene

222 (PTFE) or polycarbonate bottles. We filtered water sequentially through a $0.7-\mu \mathrm{m}$

223 (nominal pore size) GF/F filter (Whatman) and a $0.2-\mu \mathrm{m}$ filter (Omnipore, EMD 
224 Millipore) using a peristaltic pump. We re-wrapped the GF/F filters in their combusted

225 aluminum foil envelopes and we folded and placed the Omnipore filters into cryogenic

226 vials (Nalgene). We stored filters at $-80^{\circ} \mathrm{C}$ until they could be extracted in the laboratory

227 (next section).

228 We then acidified the filtrate with $4 \mathrm{~mL}$ of $12 \mathrm{M} \mathrm{HCl}(\sim \mathrm{pH}$ 2-3; Dittmar et al. 2008;

229 Longnecker 2015). We extracted dissolved organic molecules from the filtrate using solid

230 phase extraction (SPE) with a modified styrene-divinylbenzene polymer (Agilent Bond

231 Elut PPL) as a substrate. We first rinsed the PPL cartridges with $6 \mathrm{~mL}$ of methanol and

232 then used a vacuum pump to pull the acidified filtrate $(4 \mathrm{~mL}$ of $12 \mathrm{M} \mathrm{HCl}$ added to $4 \mathrm{~L}$ of

233 filtrate $(\sim \mathrm{pH} 2-3)$ through the cartridge via PTFE tubing (Dittmar et al. 2008; Longnecker

234 2015). Then we rinsed the cartridge with $\sim 24 \mathrm{~mL}$ of $0.01 \mathrm{M} \mathrm{HCl}$ and allowed it to dry by

235 pulling air over the cartridge for $5 \mathrm{~min}$. We eluted each sample with $6 \mathrm{~mL}$ of methanol

236 into a glass test tube and then transferred it via Pasteur pipette to an $8 \mathrm{~mL}$ amber vial. We

237 stored extracts at $-20^{\circ} \mathrm{C}$ until analysis. We created process blanks by carrying shipboard

238 and laboratory Milli-Q water through the entire procedure of filtration and SPE

239 extraction.

\section{Laboratory sample processing}

242 We extracted particulate filters within $48 \mathrm{~h}$ of mass spectrometry analysis. We

243 adapted the filter extraction protocol (Kido Soule et al. 2015) from Rabinowitz and

244 Kimball (2007). We weighed one half of each filter and cut it into smaller pieces using

245 methanol-rinsed scissors and tweezers on combusted aluminum foil. We placed the

246 pieces in an $8 \mathrm{~mL}$ glass amber vial with $1 \mathrm{~mL}$ of $-20^{\circ} \mathrm{C}$ extraction solvent $(40: 40: 20$ 
247 acetonitrile:methanol:water $+0.1 \mathrm{M}$ formic acid) and spiked $25 \mu \mathrm{L}$ of a $1 \mu \mathrm{g} / \mathrm{mL}$

248 deuterated standard mix (glutamic acid- $\mathrm{d}_{3}$, 4-hydroxybenzoic acid- $\mathrm{d}_{4}$, taurocholate- $\mathrm{d}_{5}$ )

249 into each sample as an extraction recovery standard. We vortexed each vial gently to

250 separate filter pieces and then sonicated the vials in an ultrasonication bath for 10 min.

251 We transferred the solvent extract with a Pasteur pipette to $1.5 \mathrm{~mL}$ Eppendorf centrifuge

252 tubes. We rinsed the filter pieces left in the $8 \mathrm{~mL}$ vials with $200 \mu \mathrm{L}$ of cold extraction

253 solvent and combined the rinse with the original extract. We spun the extract at 20,000 $\mathrm{x}$

$254 g$ for 5 min to remove cellular detritus and filter particles, and transferred the supernatant

255 to clean $8 \mathrm{~mL}$ amber glass vials for neutralization with $26 \mu \mathrm{L}$ of $6 \mathrm{M}$ ammonium

256 hydroxide. We removed the solvent by vacufuge until samples were almost completely

257 dry $(<5 \mu \mathrm{L})$ and reconstituted the dry extract with either $247.5 \mu \mathrm{L} \mathrm{95:5}$ water:acetonitrile

258 and $2.5 \mu \mathrm{L}$ biotin- $\mathrm{d}_{4}$ (injection standard) for samples collected at the surface or DCM, or

$259123.75 \mu \mathrm{L}$ 95:5 water:acetonitrile and 1.25 $\mu \mathrm{L}$ biotin- $_{4}$ (injection standard) for deeper

260 samples with presumed lower biomass. We loaded $100 \mu \mathrm{L}$ of each solution into a glass

261 insert in an autosampler vial. We combined $15 \mu \mathrm{L}$ of each sample for matrix-matched

262 quality control during the LC-MS/MS analysis (see next section).

263 For the dissolved metabolites, we brought $1 \mathrm{~mL}$ of the SPE extracts $(\sim 6 \mathrm{~mL}$ total

264 volume) to almost complete dryness in the vacufuge and then reconstituted the samples in

$265495 \mu \mathrm{L}$ 95:5 water:acetonitrile and $5 \mu \mathrm{L}$ of $5 \mu \mathrm{g} / \mathrm{mL}$ biotin- $\mathrm{d}_{4}$ (injection standard). Some

266 dissolved metabolite samples (mostly deep samples, $2000-5000 \mathrm{~m}$ ) required additional

267 dilution due to high-levels of ion suppression in the middle of the chromatogram (see

268 Table S2). 


\section{Mass spectrometry}

271 We performed the LC-MS/MS analysis on a reversed phase C18 column

272 (Phenomenex Synergi Fusion, $2.1 \times 150 \mathrm{~mm}, 4 \mu \mathrm{m}$ ) coupled via heated electrospray

273 ionization (ESI) to a triple quadrupole mass spectrometer (Thermo Scientific TSQ

274 Vantage) operated under selected reaction monitoring mode (SRM), as described

275 previously (Kido Soule et al. 2015). We monitored quantification and confirmation SRM

276 transitions for each analyte. Chromatography conditions included a gradient between

277 Eluent A (Milli-Q water with $0.1 \%$ formic acid) and Eluent B (acetonitrile with $0.1 \%$

278 formic acid) at $250 \mu \mathrm{L} / \mathrm{min}$ : hold at $5 \% \mathrm{~B}$ for $2 \mathrm{~min}$; ramp to $65 \% \mathrm{~B}$ for $16 \mathrm{~min}$; ramp to

$279100 \% \mathrm{~B}$ for $7 \mathrm{~min}$ and hold for $8 \mathrm{~min}$. We re-equilibrated the column with the starting

280 ratio of eluents for $8.5 \mathrm{~min}$ between samples. We separated samples into batches of

281 approximately 50 samples, with a pooled sample comprised of those 50 samples. We

282 conditioned the column with 5 injections of the pooled sample prior to each batch, and

283 we ran a pooled QC sample after every ten samples. These samples indicated that

284 coefficients of variation of metabolite abundance ranged between $8-27 \%$ during mass

285 spectrometry analysis.

287 Data processing

288 We converted the XCalibur RAW files generated by the mass spectrometer to mzML

289 files using msConvert (Chambers et al. 2012). We used MAVEN (Melamud et al. 2010;

290 Clasquin et al. 2012) to select and integrate peaks. We discarded calibration peaks below

291 a MAVEN quality threshold of 0.4 (on a scale of $0-1$ ) and sample peaks below 0.2 . To

292 enhance confidence in metabolite identification, we required quantification and 
293 confirmation peaks to have retention times within 12 seconds ( 0.2 minutes) of each other.

294 We required confirmation ions to have a MAVEN quality score of at least 0.1 and a

295 signal-to-noise ratio greater than 1 . We required calibration curves to have at least five

296 calibration points, with the highest point at one concentration level above the highest

297 concentration in a sample. There were 9 available calibration points: $0.5 \mathrm{ng} \mathrm{mL}^{-1}, 1 \mathrm{ng}$

$298 \mathrm{~mL}^{-1}, 10 \mathrm{ng} \mathrm{mL} L^{-1}, 25 \mathrm{ng} \mathrm{mL} L^{-1}, 50 \mathrm{ng} \mathrm{mL} L^{-1}, 100 \mathrm{ng} \mathrm{mL}{ }^{-1}, 250 \mathrm{ng} \mathrm{mL}{ }^{-1}, 500 \mathrm{ng} \mathrm{mL} L^{-1}, 1000$

$299 \mathrm{ng} \mathrm{mL} \mathrm{L}^{-1}$. We adjusted particulate metabolite abundances based on ion suppression

300 determined by comparison of a standard spiked pooled sample (1000 ng mL $\mathrm{metabolite}^{-1}$ m

301 standard mix in the sample matrix) to a standard spiked Milli-Q water sample (1000 ng

$302 \mathrm{~mL}^{-1}$ metabolite standard mix without complex matrix), (see Johnson et al. 2020 for ion

303 suppression values). We normalized metabolite abundances to the volume of seawater

304 filtered. Where noted, we normalized particulate concentrations of metabolites to the total

305 moles of targeted metabolites measured in the sample because this parameter correlated

306 well with available cell counts (see discussion below and Figure S1). We corrected the

307 concentrations of dissolved metabolites with extraction efficiencies greater than $1 \%$ on a

308 PPL cartridge (measured concentration divided by the extraction efficiency) to reflect a

309 more accurate estimate of the in situ metabolite concentrations (see extraction

310 efficiencies in Johnson et al. 2017). We do not report dissolved metabolites with

311 extraction efficiencies less than $1 \%$.

312

313 Determination of microbial community composition

314 We collected different types of microbial community composition data on the

315 southern transect (KN210-04) and the northern transect (AE1319). In the south Atlantic 
316 we used small subunit ribosomal RNA (16S or SSU rRNA) gene amplicon sequencing to

317 determine bacterial and archaeal community composition as described in Johnson et al.

318 (2020). In the north Atlantic, we used flow cytometry methods to determine abundances

319 of Synechococcus, Prochlorococcus, picoeukaryotes, and nanoeukaryotes as described in

320 Lomas et al. (2014).

321

\section{Computation and statistical tools}

323 We used MATLAB (R2014a; MathWorks, Natick, MA) to process data and create

324 figures. We created the map and metabolite profile images with Ocean Data View

325 (Schlitzer 2016). We calculated Spearman's rank correlation coefficients using the R stats

326 package (R Core Team 2015) to examine the relationship between metabolite

327 distributions and microbial community composition. Spearman's rank correlation

328 identifies monotonic relationships but does not require that the relationship be linear. We

329 required that metabolites be present in at least three samples to perform the analysis.

330 When working with the phylogenetic data from cruise KN210-04 we only included the

331 top ten most abundant phyla. We adjusted the p-values from the correlation analysis

332 using the false discovery rate algorithm in the R package q-value (Storey 2002, 2010;

333 Storey and Tibshirani 2003). We considered the resulting adjusted q-values significant at

334 the value permitting the possibility of one false positive for the smaller north Atlantic

335 dataset $(p<0.06$ particulate metabolites; $p<0.35$ dissolved metabolites). For the larger

336 south Atlantic dataset we defined the significance cut-off as $p<0.05$. We defined mixed

337 layer depth as the depth where the decreasing temperature exceeded $0.15^{\circ} \mathrm{C} \mathrm{m}^{-1}$ (based 
338 upon the continuous CTD downcast) and the euphotic zone depth as the depth at which

339 photosynthetically active radiation (PAR) was $1 \%$ of the surface PAR.

\section{$341 \quad$ Results}

\section{Oceanographic transect}

343 We collected samples along a transect encompassing latitudes from $38^{\circ} \mathrm{S}$ to $55^{\circ} \mathrm{N}$ and

344 at depths ranging from the surface $(5 \mathrm{~m})$ to approximately $5500 \mathrm{~m}$. Surface oceanic

345 regions along this transect included the South Atlantic Gyre (Stations K2, K5, K7, K9),

346 the equatorial region (Stations K12, K15, K16, K19, K21), the Amazon River plume

347 (Station K23), the North Atlantic Gyre (Stations A11, A15), and the Labrador Sea

348 (Stations A4, A7; Figure 1a) facilitating an analysis of metabolite distributions in both

349 productive and oligotrophic regions of the ocean. In addition, we took samples from deep

350 water masses including Antarctic Intermediate Water, North Atlantic Deep Water, and

351 Antarctic Bottom Water (Figure S2). Stations and depths with likely high productivity

352 were identified using chlorophyll $a$ concentrations (Figure 1c). These included the deep

353 chlorophyll maximum (DCM) near the equator where there was upwelling of nutrients

354 (station K15) and the highest latitudes sampled in the Labrador Sea (stations A4, A7)

355 where there was a shallow DCM. The total organic carbon (TOC) concentrations, as

356 expected, were maximal in the surface water of the subtropical gyres and decreased with

357 depth (Figure 1b).

359 Data normalization 
360 We report both particulate and dissolved metabolite concentrations per total volume

361 filtered (picomoles per liter, pM). This approach is the most unambiguous way to present

362 the data as concentration units are the standard chemical and geochemical approach to

363 reporting chemical data. Concentration units also facilitate comparisons between the

364 particulate and dissolved distributions. However, as particulate metabolite samples are

365 approximations of the intracellular pool of metabolites, an approach that presents

366 metabolite abundances in relation to cellular biomass is also needed. Other 'omics fields

367 use approaches such as normalization to housekeeping genes (whose abundances are

368 constant inside cells) to present per-cell variability. Such an approach is not possible here

369 because there is no consensus "housekeeping" metabolite. We considered other

370 oceanographic parameters as proxies for biomass such as chlorophyll $a$ concentration or

371 the beam transmittance at $660 \mathrm{~nm}$ (from a transmissometer) as a measure of how many

372 particles were in the water. Chlorophyll $a$ is problematic because it is only produced by

373 phytoplankton, and its abundance can be affected by physiological changes (Kruskopf

374 and Flynn 2006). The relationship between transmissometer data and prokaryotic cell

375 counts (from SYBR Green staining and counting under an epifluorescence microscope)

376 showed a poor relationship. In this study, we predominantly use pM units, but present

377 some data as the mole fraction where the moles of the metabolite are normalized to the

378 total moles of metabolites measured in the sample. This was selected because there is

379 good agreement between prokaryotic cell abundance and total moles of metabolites

380 measured (Figure S1). As more oceanographic measurements of metabolites become

381 available, best practices in normalization will inevitably emerge. 


\section{Variability in metabolite detection}

384 Of the 32 metabolites that passed the quality control checks of their calibration curves

385 in the particulate samples, 5 were not detected in any sample. 2,3-Dihydroxybenzoic acid

386 (2,3-DHBA), desthiobiotin, indole 3-acetic acid, and inosine 5'-monophosphate (IMP)

387 were each measured in only one sample preventing assessment of their variability across

388 the full transect. Most of the remaining metabolites were elevated in the upper $200 \mathrm{~m}$ of

389 the water column, with DMSP, guanine, and phenylalanine measured in every particulate

390 sample in this depth range. Throughout the full water column, guanine and phenylalanine

391 were measured in all but 3 samples (Table 1).

392 Twenty-six dissolved metabolites passed quality control criteria for their calibration

393 curves and could be extracted using our PPL SPE method (Johnson et al. 2017). Of these,

3948 were not detected in any samples. In some cases, this may be due to extremely low

395 solid phase extraction efficiencies (i.e., high detection limits). No metabolites were

396 measured in every sample in the dissolved phase. However, phenylalanine was the most

397 prevalent of the dissolved metabolites, detected in $70 \%$ of these samples. $4-$

398 Aminobenzoic acid (PABA), pantothenic acid (vitamin $\mathrm{B}_{5}$ ), and tryptophan were present

399 in most samples from the upper $200 \mathrm{~m}$ (Table 2). We examined the relationship between

400 dissolved and particulate metabolites and based on the observed lack of a consistent

401 relationship, we believe that filtration-induced cell leakage did not have a significant

402 impact on our data and its interpretation (Text S1).

404 Microbial taxa abundance 
405 The datasets used to describe the composition of the microbial community were

406 generated with different analytical approaches between the two cruises, and are not

407 directly comparable. For both cruises, flow cytometry provided an assessment of the

408 pigmented phytoplankton, including cyanobacteria Prochlorococcus and Synechococcus,

409 picoeukaryotes and nanoeukaryotes. In the northern Atlantic (Figure S3),

410 Prochlorococcus was numerically the largest of these four groups in the subtropics

411 (Figure S3; stations A11 and A15) and a small component of stations A4 and A7, where

412 Synechococcus and picoeukaryotes were most abundant (Baer et al. 2017).

413 Prochlorococcus was numerically more abundant in the surface waters of the south and

414 equatorial Atlantic than Synechococcus, picoeukaryotes, and nanoeukaryotes (Howard et

415 al. 2017). In the southern and equatorial Atlantic, phytoplankton data were complemented

416 by the prokaryotic community composition based on 16S rRNA gene sequences (Figure

417 S4). Consistent with the literature on pelagic prokaryotic communities (Frias-Lopez et al.

418 2008), Cyanobacteria, Proteobacteria, and Bacteroidetes were the most abundant phyla in

419 the upper $200 \mathrm{~m}$ (Figure S4). Cyanobacteria, specifically Prochlorococcus, was a more

420 abundant component of the microbial community at the surface, at every station along

421 this transect except for stations A4 and A7. This is consistent with the overall

422 understanding of the distribution of these groups in the ocean (Zubkov et al. 1998; Li and

423 Harrison 2001; Flombaum et al. 2013).

425 Trends in particulate metabolites

426 Most particulate metabolites were elevated in the upper $200 \mathrm{~m}$ of the water column,

427 relative to deeper samples (e.g. Figure 2) and 15 of the 27 quantified metabolites were 
428 found more frequently in the upper $200 \mathrm{~m}$ than below that depth (Table 1). These results

429 are consistent with expectations based on the higher productivity and more abundant

430 biomass in this zone. For example, guanine, a purine nucleobase required by all living

431 organisms, was measured in nearly all the samples in the transect allowing comparison of

432 its concentrations at all depths. Particulate guanine abundance was relatively high in the

433 surface samples, generally peaking at the DCM, and then was quite low at depth (Figure

434 2a). As an essential component of DNA, guanine is a metabolite that might be

435 hypothesized to co-vary with cell abundance. While the relationship between guanine and

436 proxies of biomass such as prokaryotic cell abundance $\left(\mathrm{r}^{2}=0.61, p<0.001\right)$ and

437 chlorophyll $a$ concentration $\left(\mathrm{r}^{2}=0.62, p<0.001\right)$ was statistically significant, more study

438 is required before it could be used as a proxy of biomass. When guanine is normalized to

439 the total moles of targeted metabolites measured in a sample, it becomes a major

440 component of the deep samples reaching greater than $70 \%$ of the total moles of

441 metabolites in some samples (Figure 2b).

442 To examine relationships between particulate metabolites and the distribution of

443 microbial taxa, we used Spearman's rank correlation coefficients to determine the extent

444 of positive or negative co-variance. In the south and equatorial Atlantic, Cyanobacteria

445 and Actinobacteria had the most significant positive correlations with many of the

446 particulate metabolites, closely followed by Bacteroidetes and Proteobacteria (Figure 3a).

447 Arginine and caffeine had significant positive correlations with other phyla (Figure 3a).

448 In the north Atlantic, we observed a similar trend, wherein nanoeukaryotes,

449 picoeukaryotes, and Synechococcus were generally positively correlated with most

450 metabolites and Prochlorococcus was negatively correlated with metabolite abundance 
451 (Figure 3b). Uracil and adenine were the metabolites most weakly correlated with

452 microbial taxa in both the south and north Atlantic. Additionally, in the south Atlantic

453 biotin, folic acid, and methionine were not significantly correlated with any of the 10

454 most abundant phyla (Figure 3) suggesting that other factors control their distributions.

455 Thus, particulate metabolites fall generally into two groups: 1) those that positively

456 correlate with abundant taxa or 2) those that do not have correlations with specific taxa.

457 Adenosine 5'-monophosphate (AMP) is representative of the distributions seen for

458 metabolites that positively correlated with abundant taxa (Figure 4a) and had a linear $\left(\mathrm{r}^{2}\right.$

$459=0.79, p<0.001)$ correlation with chlorophyll $a$ concentrations (Figure $4 \mathrm{~b}$ ). These

460 metabolites (phenylalanine, tryptophan, inosine, AMP, glutamic acid, 5-

461 methylthioadenosine (MTA), adenosine, DMSP, guanine, glycine betaine) were

462 characterized by elevated concentrations at high latitudes in the north Atlantic, at the

463 DCM at K15 where upwelling was observed, and at the surface of K23 where there was

464 some influence from the Amazon River plume. Relatively low concentrations were

465 measured in the surface at K7, K9, and K12 in the South Atlantic Subtropical Gyre.

466 These metabolites also grouped with the summed total moles of metabolites measured in

467 each sample, indicating that they account for the bulk of the molar abundance of

468 metabolites detected (Figure 3).

469 Below $200 \mathrm{~m}$, the amino acids phenylalanine, tryptophan, (iso)leucine, proline

470 (Figure 5b), and arginine (Figure 5a), and the purine nucleobases guanine and adenine

471 were detected (Table 1). Guanine in particular was found in most deep samples (Figure

472 2). Caffeine was also measured in deep samples and was strongly positively correlated

473 with some of the other deep metabolites (guanine, phenylalanine, tryptophan). Given our 
474 limited knowledge of caffeine in the ocean, we cannot constrain whether caffeine's

475 presence is due to production by an organism as a defense compound similar to terrestrial

476 plants (Mithöfer and Boland 2012) or from some other source, but its depth profile is not

477 consistent with ship contamination. Finally, the B vitamins biotin $\left(\mathrm{B}_{7}\right)$ and pyridoxine

$478\left(\mathrm{~B}_{6}\right)$, were measured below the euphotic zone. Biotin was measured in only a few deep

479 samples while pyridoxine, an essential cofactor in many enzymes associated with amino

480 acid metabolism (Mittenhuber 2001), was more prevalent. It is striking that of all the B

481 vitamins measured, pyridoxine was present at a variety of depths with relatively

482 consistent concentrations, suggesting that this vitamin might be of particular importance

483 to deep sea microbes.

484

485 Trends in dissolved metabolites

486 The distributions of dissolved metabolites in the upper $250 \mathrm{~m}$ were weakly correlated

487 with prokaryotic taxa in the south Atlantic. This correlation was conducted on all samples

488 down to $250 \mathrm{~m}$ to provide enough statistical power to make the comparison and to

489 include data that contrasted with the more productive surface and DCM samples. In the

490 north Atlantic, the dissolved metabolites were positively correlated with either

491 nanoeukaryotes and picoeukaryotes or with Synechococcus (Figure 6). While few

492 correlations were significant after a false discovery rate correction, we observed similar

493 trends within the correlations from both the south and north Atlantic, underscoring the

494 potential links between microbial taxa and dissolved metabolites. For example, in the

495 south Atlantic, dissolved PABA and pantothenic acid, had significant positive

496 correlations with Cyanobacteria, likely driven by the abundance of Prochlorococcus 
497 (Figure 6a). In the north Atlantic, dissolved MTA was positively correlated with both

498 picoeukaryotes and nanoeukaryotes, while pantothenic acid was positively correlated

499 with Synechococcus. In the same region, Prochlorococcus was generally negatively

500 correlated with the dissolved metabolites, most strongly with riboflavin. These results

501 suggest that some dissolved metabolites are linked to differing taxa across the transect.

502 As the dominant Cyanobacteria genus shifts from Prochlorococcus in the south to

503 Synechococcus in the north, dissolved pantothenic acid and PABA could be differentially

504 derived from each genus, including in the northernmost samples (stations A4 and A7)

505 where picoeukaryotes are also more abundant (Figure S3). In contrast, dissolved MTA

506 and riboflavin were detected in relatively few samples in the south Atlantic, but were

507 particularly abundant in the northernmost stations of the transect where picoeukaryotes

508 and Synechococcus were more abundant than Prochlorococcus (Figures 6 and 7).

510 Discussion

\section{Comparison to previously measured concentrations}

512 Some of the metabolites presented here have been measured previously; in some

513 cases, using similar mass spectrometry-based methods or with other analytical

514 approaches. While the abundances of particulate metabolites are difficult to compare due

515 to the diversity of ways in which molecules are normalized, concentrations of dissolved

516 metabolites can be compared more readily with past values. Of the 18 dissolved

517 metabolites quantified here, 12 have been measured previously in aquatic systems (Table

518 S3). Two B vitamins, biotin $\left(\mathrm{B}_{7}\right)$ and riboflavin $\left(\mathrm{B}_{2}\right)$, had values of the same order of

519 magnitude as the measurements made by Sañudo-Wilhelmy et al. (2012). A third B 
520 vitamin, thiamin $\left(\mathrm{B}_{1}\right)$, had an order of magnitude higher concentration than that reported

521 by Sañudo-Wilhelmy et al. (2012), but was only measured in one sample. Thiamin has a

522 low extraction efficiency in the current protocol (2\% in seawater; Johnson et al. 2017)

523 and the resulting correction may introduce quantification error. When measured as

524 dissolved free amino acids, (iso)leucine, phenylalanine, and tryptophan display a variety

525 of concentrations ranging from hundreds to thousands of picomolar (Mopper and

526 Lindroth 1982) in the upper $170 \mathrm{~m}$ of the Baltic Sea. In our study, concentrations varied

527 from $<10 \mathrm{pM}$ (deep ocean) to hundreds of $\mathrm{pM}$ (surface ocean). In short, dissolved

528 metabolite concentrations obtained using this method agreed within an order of

529 magnitude with existing data, where available.

530

531 Many particulate metabolite distributions in the euphotic zone are linked to

532 abundant microbial taxa

533 In the euphotic zone, many particulate metabolites have fairly similar profiles.

534 Concentrations (Figure 3) differ most likely due to shifts in microbial community

535 composition where members retain relatively constant intracellular concentrations of

536 essential metabolites. For example, guanine (Figure 2) and AMP (Figure 4) were both

537 elevated at the DCM and correlate with chlorophyll $a$. In the south and equatorial

538 Atlantic, the phyla of Cyanobacteria, Actinobacteria, Proteobacteria, and Bacteroidetes

539 positively correlated with particulate guanine, AMP, and other metabolites with similar

540 profiles suggesting that they may be sources of these metabolites and thus have a strong

541 influence on their distributions (Figure 3a). In the north Atlantic, nanoeukaryotes,

542 picoeukaryotes, and Synechococcus were generally positively correlated with a similar 
543 set of metabolites, while Prochlorococcus was negatively correlated with these

544 metabolite abundances (Figure 3b). This is likely a function of which taxa are the most

545 abundant as these taxa will have the greatest impact on essential metabolite

546 concentrations. It is also consistent with biovolume considerations, wherein larger

547 microbes such as the pico- and nanoeukaryotes and Synechococcus carry larger

548 metabolite concentrations due to their size, relative to the small Prochlorococcus

549 (Kirchman 2008).

550 In contrast, some metabolites were not positively correlate with microbial abundance

551 (Figure 3), including two B vitamins, a number of amino acids, and a nucleobase

552 (adenine) and nucleobase derivatives (xanthine, uracil, caffeine). Adenine, a purine

553 nucleobase, is an example of a metabolite that has weak or negative correlations with the

554 dominant microbial taxa. It is measured in most surface samples, but in relatively few

555 DCM samples compared to metabolites that positively correlate with Cyanobacteria,

556 Proteobacteria and/or pico- and nanoeukaryotes. It is particularly striking that adenine

557 was not detected at the Station K15 DCM where nutrients were being upwelled. In

558 contrast, some of its highest concentrations were measured in the surface at Stations K5

559 and K7 in the oligotrophic South Atlantic Subtropical Gyre. This distinct pattern in

560 particulate adenine distribution may be linked to how microbes respond to nutrient stress.

561 In culture, Escherichia coli responds to both carbon and nitrogen starvation by elevating

562 intracellular concentrations of adenine (Brauer et al. 2006). While the mechanism for this

563 increase is not known, intracellular adenine concentrations play a regulatory role by

564 binding to certain riboswitches (reviewed by Winkler and Breaker 2005). There are some

565 exceptions to this trend of particulate adenine concentrations being elevated in 
566 oligotrophic samples. In particular, adenine was not detected at Station K9 in the gyre

567 and the greatest adenine abundance was at Station K23 in the Amazon River plume.

568 Thus, particulate adenine concentrations may be driven by something more complex than

569 simply nutrient limitation, such as type or quality of nutrients, and variable species-

570 specific responses. Metabolite distributions that are independent of biomass may

571 highlight subtle and perhaps highly transient differences in metabolic state that are not

572 reflected in more conservatively maintained intracellular metabolites.

573

574 Variable patterns in the distribution of dissolved metabolites

575 Not all particulate and dissolved metabolites could be compared because some

576 metabolites are not retained on the PPL polymer used to extract the dissolved metabolites

577 (Johnson et al. 2017). In addition, some dissolved metabolites were not detected in

578 particulate samples. Nevertheless, where data could be compared between particulate and

579 dissolved pools, we observed greater variability in the distribution of dissolved

580 metabolites. In rare cases, such as tryptophan and phenylalanine, the particulate and

581 dissolved abundances appeared to co-vary (phenylalanine, $\mathrm{r}^{2}=0.77$; tryptophan, $\mathrm{r}^{2}=$

582 0.73), implying a direct relationship between intracellular production and subsequent

583 release into the water, as well as a fairly constant rate of removal. More frequently, we

584 observed distinct distributions between the dissolved and particulate pools, and, in some

585 cases, notable differences between the distributions of dissolved metabolites in the

586 northern and southern portions of the transect (Figure 7; Figure 8).

587 For example, PABA and pantothenic acid were positively correlated with

588 Cyanobacteria in the southern portion of the transect and pantothenic acid was positively 
589 correlated with Synechococcus in the northern portion of the transect (Figure 6). Both

590 PABA and pantothenic acid were particularly elevated in surface samples and measured

591 throughout the transect (Figure 7a), suggesting a common source such as the

592 Cyanobacteria. Due to its high rates of photosynthesis (Hartmann et al. 2014),

593 Prochlorococcus can release between 9 and 24\% of its initially assimilated inorganic

594 carbon as DOC (Bertilsson et al. 2005). Of that, 4-20\% can be low molecular weight

595 carboxylic acids which include molecules like PABA and pantothenic acid (Bertilsson et

596 al. 2005). Functionally, pantothenic acid is synthesized by plants and microbes and is a

597 precursor to coenzyme A and acyl carrier protein. PABA is a precursor to the vitamin

598 folate (Gibson and Pittard 1968). Both of these molecules could be valuable

599 micronutrients within the microbial community. In a recent study identifying auxotrophy

600 in the genomes of host-associated gram negative bacteria, some bacteria were predicted

601 to be auxotrophic for both of these metabolites (Seif et al. 2020). Although there is no

602 current evidence showing auxotrophy for these molecules in marine microbes, sustained

603 environmental presence could provide the right conditions for loss of those biosynthetic

604 pathways in some microbes (D’Souza and Kost 2016).

605 In contrast to PABA and pantothenic acid, riboflavin was more prevalent in the DCM

606 and the northern portion of the transect (Figure 7b). Riboflavin has no correlation with

607 any prokaryotic phyla in the south and equatorial Atlantic. However, in the north

608 Atlantic, while the p-values are not statistically significant, we determined a weak

609 positive correlation with Synechococcus and pico/nanoeukaryotes, and a significant

610 negative correlation with Prochlorococcus (Figure 6). These correlations suggest that the

611 source of dissolved riboflavin might be eukaryotes rather than Cyanobacteria. Riboflavin 
612 is a vitamin that could play a role as a micronutrient within the microbial community.

613 Unlike some other B vitamins, auxotrophy for riboflavin has not been documented to our

614 knowledge. However, it is likely that microbes would assimilate available riboflavin

615 rather than synthesize it de novo. In non-marine systems, riboflavin plays other roles such

616 as mimicking quorum sensing molecules (Rajamani et al. 2008) and priming plant

617 defense responses (Zhang et al. 2009). The versatility of this molecule suggests we may

618 not fully understand its role in marine systems.

619 Dissolved MTA had a similar distribution to riboflavin but was detected in fewer

620 samples in the south Atlantic (Figure 8b). Nevertheless, it was detected in many

621 particulate samples in both the north and south Atlantic, indicating an intracellular

622 presence throughout the transect (Figure 8a). This is consistent with our understanding of

623 MTA biochemistry, wherein intracellular excess MTA inhibits the enzymes that produce

624 it, leading to relatively constant internal concentrations (Raina et al. 1982; Parsek et al.

625 1999). The latitudinal profile of particulate MTA shows a similar distribution to the other

626 metabolites linked to the most common prokaryotic phyla along the transect. The highest

627 abundances of particulate MTA are at stations A4, A7, the DCM at K15, and the surface

628 at K23. The particulate MTA abundances were lower, but still elevated, in most DCM

629 samples and in the north Atlantic where it was positively correlated with pico- and nano-

630 eukaryotes (Figure 3; Figure 8a). In contrast, dissolved MTA was only measured in the

631 north Atlantic and at the surface in K23 (Amazon River plume station; Figure 8b).

632 This difference in MTA distributions between particulate and dissolved pools

633 suggests that the intracellular concentration of MTA does not directly determine the

634 dissolved MTA concentration, unlike the aromatic amino acids tryptophan and 
635 phenylalanine. In the south Atlantic, dissolved MTA was detected in too few samples to

636 compare to the community composition. In the north Atlantic, like riboflavin, dissolved

637 MTA was positively correlated with pico- and nanoeukaryotes (Figure 6), suggesting that

638 in the dissolved phase MTA might be associated with eukaryotic taxa. Alternatively,

639 while this cannot be determined from this dataset, there could be a more rapid removal

640 process for dissolved MTA in the south Atlantic that maintains the dissolved

641 concentrations below detection. However, a comparison of some representative genomes

642 suggests that the distribution of dissolved MTA could be shaped by differences in a

643 metabolic pathway between taxa. In culture experiments, the Cyanobacterium,

644 Synechococcus elongatus, does not release MTA (Fiore et al. 2015) while the

645 heterotrophic bacterium, Ruegeria pomeroyi, does (Johnson et al. 2016). According to the

646 KEGG database, S. elongatus, and other Synechococcus and Prochlorococcus species

647 lack the final gene in the methionine salvage pathway through which MTA is recycled

648 back to methionine, providing the possibility that MTA could be further transformed

649 through five additional enzymatic reactions before being released from the cell (Kanehisa

650 and Goto 2000; Kanehisa et al. 2012). In contrast, $R$. pomeroyi, has a truncated

651 methionine salvage pathway with only one additional possible downstream reaction after

652 MTA. This reaction results in a phosphorylated metabolite that would be a costly waste

653 product under low phosphorus conditions (Kanehisa and Goto 2000; Kanehisa et al.

654 2012). This suggests that rather than perform the final phosphorylation reaction, MTA

655 might be released as a waste product as was observed in Johnson et al. (2016). Similarly,

656 the picoeukaryotes Ostreococcus tauri and Micromonas pusilla also have a truncated

657 methionine salvage pathway that ends with the same phosphorylated metabolite as $R$. 
658 pomeroyi (Kanehisa and Goto 2000; Kanehisa et al. 2012), suggesting that a higher

659 abundance of picoeukaryotes could result in more dissolved MTA.

660

\section{Particulate metabolites that persist in the deep ocean}

662 The metabolites measured in the deep ocean must either be derived from its unique

663 resident microbial community or be delivered from the surface ocean by sinking

664 particles. Interestingly, in a study that sought to establish a degradation index for

665 particulate organic matter based on amino acid composition, Dauwe et al. (1999) found

666 that threonine, arginine, aspartic acid and glycine increased as a mole percent of total

667 amino acids with increasing organic matter degradation. While we did not quantify

668 threonine, aspartic acid, or glycine in this study, we observed arginine in many deep

669 samples (Figure 5a). While these amino acids are used as part of a degradation index for

670 particulate organic matter (Dauwe et al. 1999), it is unclear whether their increased

671 proportion in deep particulate organic matter is due to in situ production or selective

672 preservation on sinking particles. We measured tryptophan and phenylalanine throughout

673 the deep particulate samples. These amino acids are not linked to organic matter

674 degradation according to Dauwe et al. (1999), suggesting that they might be produced by

675 the microbial community at depth. However, data from sinking particles collected at 150

$676 \mathrm{~m}$ along the south Atlantic transect indicate that phenylalanine and tryptophan are present

677 in these sinking particles all along the transect, while arginine was only detected in $\sim 25 \%$

678 of the sinking particle samples (Johnson et al. 2020) suggesting that phenylalanine and

679 tryptophan could be delivered by sinking particles but that arginine might be generated in 680 situ. 
681 Other particulate metabolites that we might expect to measure in the deep ocean

682 include osmolytes, which are present at high concentrations in the cytosol of cells.

683 However, glycine betaine and glutamic acid, both common osmolytes across all domains

684 of life (Yancey et al. 1982) and present at high concentrations in the upper water column

685 in this study were not detected in the deep ocean. By contrast, guanine and phenylalanine

686 had similar concentrations to glycine betaine and glutamic acid in the euphotic zone, but

687 were also measured in the deep ocean. This suggests that glycine betaine and glutamic

688 acid decrease more quickly than biomass with depth. This may indicate that other

689 molecules are used as osmolytes by deep-sea microbes due to differing requirements of

690 organisms living in the colder, higher pressure waters of the ocean interior. Deep sea

691 invertebrates have been shown to use different osmolytes than surface organisms but, to

692 our knowledge, this has not been examined in marine microbes (Yancey et al. 2002). The

693 amino acid proline also functions as an osmolyte (Burg and Ferraris 2008) and was

694 measured in many deep samples, perhaps indicating a preferential use of this molecule as

695 an osmolyte at high hydrostatic pressure and low temperatures (Figure 5b). In laboratory

696 experiments, proline has been found to increase intracellularly with increasing osmolarity

697 in Bacillus subtilis (Brill et al. 2011) and in Sulfurimonas denitrificans (Götz et al. 2018).

698 While $S$. denitrificans was isolated from a tidal mudflat, other species in this genus have

699 been found around hydrothermal vents in the deep ocean (Götz et al. 2018). It has not

700 been widely characterized in studies of marine amino acid distributions, but recent work

701 found that L-proline comprised $46 \%$ of the total (free and hydrolysable) amino acids in

702 bacterial-sized particles $(0.2 \mu \mathrm{m}-1.2 \mu \mathrm{m}$; Takasu and Nagata 2015). These studies

703 support the idea that proline may be a substantial component of the cytosol of some cells 
704 in marine environments, including in the deep ocean. In the surface ocean osmolytes like

705 DMSP are important sources of organic carbon that support heterotrophic growth, and it

706 is possible that molecules such as proline may serve a similar function for deep ocean

707 heterotrophs.

\section{Conclusion}

710 By simultaneously measuring a suite of metabolites in a variety of oceanic regions

711 and depths, we have developed a better understanding of metabolite variability in the

712 ocean. We found that a group of metabolites remains constant relative to biomass,

713 specifically associated with Cyanobacteria, Proteobacteria and/or eukaryote abundances,

714 while other metabolites exhibited distinct distributions. Metabolites that deviated from

715 biomass include nucleic acids, B vitamins, amino acids, and a variety of metabolic

716 intermediates. While in many cases these metabolites have been studied in a biomedical

717 context or in a model organism and their function in the cell is known, surprisingly little

718 is known about how these molecules respond to environmental cues or their specificity

719 within certain species (particularly in the ocean). This creates challenges in interpreting

720 these data in the environment. There are surprises, such as the finding that particulate

721 adenine was distributed in way that is not linked to abundant prokaryotic taxa, that

722 dissolved metabolites like PABA and pantothenic acid might be linked to Cyanobacterial

723 abundance while MTA and riboflavin appeared linked to pico- and nanoeukaryotes, and

724 that proline was a prevalent amino acid in the deep sea. This dataset provides a context

725 for future marine metabolomics work to constrain the ways in which specific metabolites

726 may act as currencies that link diverse groups of microbes. Integrating metabolomics 
727 datasets with other omics datasets in the context of environmental parameters will allow

728 further testing of hypotheses proposed here. In addition, controlled culture experiments

729 can continue to expand our understanding of how metabolites respond to the

730 environment, and additional field studies will complete the picture of metabolite

731 distributions in other ocean regions. As this understanding is expanded, the mechanisms

732 that control the flux of these metabolites through the marine food web and carbon cycle

733 may be clarified and more accurately predicted.

735 Acknowledgments

736 Funding for this work came from a National Science Foundation grant (Grant

737 OCE-1154320 to EBK and KL). The instruments in the WHOI FT-MS Facility were

738 purchased with support from the GBMF and NSF. Support for WMJ was provided by a

739 National Defense Science and Engineering Fellowship. We thank the captains and crew

740 of the R/V Knorr and the R/V Atlantic Explorer, Catherine Carmichael, Gwenn Hennon

741 (Chl $a$ calibration on KN210-04), and Erin Eggleston (prokaryotic cell counts on KN210-

742 04) for helping to make this dataset possible. Targeted metabolomics datasets have been

743 archived with MetaboLights (study \# MTBLS1752). Sequencing was performed under

744 the auspices of the US Department of Energy (DOE) JGI Community Science Program

745 (CSP) project (CSP 1685) supported by the Office of Science of US DOE Contract DE-

746 AC02-05CH11231. Additional work related to sample collection and processing was

747 supported by the G. Unger Vetlesen and Ambrose Monell Foundations, the Natural

748 Sciences and Engineering Research Council of Canada (NSERC), the Canadian Institute

749 for Advanced Study (CIFAR) and the Canada Foundation for Innovation through grants 
bioRxiv preprint doi: https://doi.org/10.1101/2021.03.09.434501; this version posted March 9, 2021. The copyright holder for this preprint (which was not certified by peer review) is the author/funder, who has granted bioRxiv a license to display the preprint in perpetuity. It is made available under aCC-BY-NC 4.0 International license.

750 awarded to SJH. MPB was supported by a CIFAR Global Scholarship and NSERC

751 postdoctoral fellowship.

752

753 
754

755

756

757

758

759

760

761

762

763

764

765

766

767

768

769

770

771

772

773

774

775

776

777

778

779

780

781

782

783

784

785

786

787

788

789

790

791

792

793

794

795

796

797

798

799

\section{References}

Aluwihare, L., D. Repeta, and R. Chen. 1997. A major biopolymeric component to dissolved organic carbon in surface sea water. Nature 387: 166-169.

Ankrah, N. Y. D., A. L. May, J. L. Middleton, and others. 2014. Phage infection of an environmentally relevant marine bacterium alters host metabolism and lysate composition. ISME J. 8: 1089-1100. doi:10.1038/ismej.2013.216

Arar, E. J., and G. B. Collins. 1997. Method 445.0: In vitro determination of chlorophyll $a$ and pheophytin $a$ in marine and freshwater algae by fluorescence.

Barak-Gavish, N., M. J. Frada, P. A. Lee, and others. 2018. Bacterial virulence against an oceanic bloom-forming phytoplankter is mediated by algal DMSP. 1-38.

Bertilsson, S., O. Berglund, M. J. Pullin, and S. W. Chisholm. 2005. Release of dissolved organic matter by Prochlorococcus. Vie Milieu 55: 225-231. doi: 10.4319/lo.2007.52.2.0798

Brauer, M. J., J. Yuan, B. D. Bennett, W. Lu, E. Kimball, D. Botstein, and J. D. Rabinowitz. 2006. Conservation of the metabolomic response to starvation across two divergent microbes. Proc. Natl. Acad. Sci. U. S. A. 103: 19302-19307. doi: 10.1073/pnas.0609508103

Brill, J., T. Hoffmann, M. Bleisteiner, and E. Bremer. 2011. Osmotically controlled synthesis of the compatible solute proline is critical for cellular defense of Bacillus subtilis against high osmolarity. J. Bacteriol. 193: 5335-5346. doi:10.1128/JB.05490-11

Burg, M. B., and J. D. Ferraris. 2008. Intracellular organic osmolytes: Function and regulation. J. Biol. Chem. 283: 7309-7313. doi:10.1074/jbc.R700042200

Carini, P., E. O. Campbell, J. Morré, and others. 2014. Discovery of a SAR11 growth requirement for thiamin's pyrimidine precursor and its distribution in the Sargasso Sea. ISME J. 8: 1727-38. doi:10.1038/ismej.2014.61

Carlson, C. A., and D. A. Hansell. 2015. DOM sources, sinks, reactivity, and budgets, p. 65-102. In D.A. Hansell and C.A. Carlson [eds.], Biogeochemistry of marine dissolved organic matter. Elsevier.

Chambers, M. C., B. Maclean, R. Burke, and others. 2012. A cross-platform toolkit for mass spectrometry and proteomics. Nat. Biotechnol. 30: 918-920. doi:10.1038/nbt.2377

Clasquin, M. F., E. Melamud, and J. D. Rabinowitz. 2012. LC-MS data processing with MAVEN: A metabolomic analysis and visualization engine. Curr. Protoc. Bioinforma. 37: 1-23. doi:10.1002/0471250953.bi1411s37

Croft, M. T., M. J. Warren, and A. G. Smith. 2006. Algae need their vitamins. Eukaryot. Cell 5: 1175-1183. doi:10.1128/EC.00097-06

D’Souza, G., and C. Kost. 2016. Experimental evolution of metabolic dependency in bacteria. PLOS Genet. 12: 1-27. doi:10.5061/dryad.9b47j

Dauwe, B., J. J. Middelburg, P. M. J. Herman, and C. H. R. Heip. 1999. Linking diagenetic alteration of amino acids and bulk organic matter reactivity. Limnol. Oceanogr. 44: 1809-1814. doi:10.4319/lo.1999.44.7.1809

Dittmar, T., B. Koch, N. Hertkorn, and G. Kattner. 2008. A simple and efficient method for the solid-phase extraction of dissolved organic matter (SPE-DOM) from seawater. Limnol. Oceanogr. Methods 6: 230-235. doi:10.4319/1om.2008.6.230 
800

801

802

803

804

805

806

807

808

809

810

811

812

813

814

815

816

817

818

819

820

821

822

823

824

825

826

827

828

829

830

831

832

833

834

835

836

837

838

839

840

841

842

843

844

845

Dittmar, T., and B. P. Koch. 2006. Thermogenic organic matter dissolved in the abyssal ocean. Mar. Chem. 102: 208-217. doi:10.1016/j.marchem.2006.04.003

Ducklow, H. W. 1999. Minireview: The bacterial content of the oceanic euphotic zone. FEMS Microbiol. 30: 1-10. doi:10.1016/S0168-6496(99)00031-8

Fiehn, O. 2002. Metabolomics-the link between genotypes and phenotypes. Plant Mol. Biol. 48: 155-71.

Fiore, C. L., K. Longnecker, M. C. Kido Soule, and E. B. Kujawinski. 2015. Release of ecologically relevant metabolites by the cyanobacterium, Synechococcus elongatus CCMP 1631. Environ. Microbiol. 17: 3949-3963. doi:10.1111/1462-2920.12899

Flombaum, P., J. L. Gallegos, R. A. Gordillo, and others. 2013. Present and future global distributions of the marine Cyanobacteria Prochlorococcus and Synechococcus. Proc. Natl. Acad. Sci. U. S. A. 110: 9824-9829. doi:10.1073/pnas.1307701110

Frias-Lopez, J., Y. Shi, G. W. Tyson, M. L. Coleman, S. C. Schuster, S. W. Chisholm, and E. F. Delong. 2008. Microbial community gene expression in ocean surface waters. Proc. Natl. Acad. Sci. U. S. A. 105: 3805-10. doi:10.1073/pnas.0708897105

Gebser, B., and G. Pohnert. 2013. Synchronized regulation of different zwitterionic metabolites in the osmoadaption of phytoplankton. Mar. Drugs 11: 2168-2182. doi: $10.3390 / \mathrm{md} 11062168$

Gibson, F., and J. Pittard. 1968. Pathways of biosynthesis of aromatic amino acids and vitamins and their control in microorganisms. Bacteriol. Rev. 32: 465-492.

Götz, F., K. Longnecker, M. C. Kido Soule, K. W. Becker, J. Mcnichol, E. B. Kujawinski, and S. M. Sievert. 2018. Targeted metabolomics reveals proline as a major osmolyte in the chemolithoautotroph Sulfurimonas denitrificans. Microbiologyopen 1-7. doi:10.1002/mbo3.586

Hansell, D. A., C. A. Carlson, D. J. Repeta, R. Schlitzer, and I. N. Insights. 2009. Dissolved organic matter in the ocean. Oceanography 22: 202-211.

Hertkorn, N., R. Benner, M. Frommberger, P. Schmitt-Kopplin, M. Witt, K. Kaiser, A. Kettrup, and J. I. Hedges. 2006. Characterization of a major refractory component of marine dissolved organic matter. Geochim. Cosmochim. Acta 70: 2990-3010. doi:10.1016/j.gca.2006.03.021

Howard, E. M., C. A. Durkin, G. M. M. Hennon, F. Ribalet, and R. H. R. Stanley. 2017. Biological production, export efficiency, and phytoplankton communities across $8000 \mathrm{~km}$ of the South Atlantic. Global Biogeochem. Cycles 31: 1066-1088. doi:10.1002/2016GB005488

Johnson, W. M., M. C. Kido Soule, and E. B. Kujawinski. 2016. Evidence for quorum sensing and differential metabolite production by a marine bacterium in response to DMSP. ISME J. 10: 2304-2316. doi:10.1038/ismej.2016.6

Johnson, W. M., M. C. Kido Soule, and E. B. Kujawinski. 2017. Extraction efficiency and quantification of dissolved metabolites in targeted marine metabolomics. Limnol. Oceanogr. Methods 15: 417-428. doi:10.1002/lom3.10181

Johnson, W. M., K. Longnecker, M. C. Kido Soule, W. A. Arnold, M. P. Bhatia, S. J. Hallam, B. A. S. Van Mooy, and E. B. Kujawinski. 2020. Metabolite composition of sinking particles differs from surface suspended particles across a latitudinal transect in the South Atlantic. Limnol. Oceanogr. 65: 111-127. doi:10.1002/lno.11255

Kaiser, K., and R. Benner. 2009. Biochemical composition and size distribution of organic matter at the Pacific and Atlantic time-series stations. Mar. Chem. 113: 63- 
846

847

848

849

850

851

852

853

854

855

856

857

858

859

860

861

862

863

864

865

866

867

868

869

870

871

872

873

874

875

876

877

878

879

880

881

882

883

884

885

886

887

888

889

890

891

77. doi:10.1016/j.marchem.2008.12.004

Kanehisa, M., and S. Goto. 2000. KEGG: kyoto encyclopedia of genes and genomes. Nucleic Acids Res. 28: 27-30.

Kanehisa, M., S. Goto, Y. Sato, M. Furumichi, and M. Tanabe. 2012. KEGG for integration and interpretation of large-scale molecular data sets. Nucleic Acids Res. 40: D109-D114. doi:10.1093/nar/gkr988

Kido Soule, M. C., K. Longnecker, W. M. Johnson, and E. B. Kujawinski. 2015. Environmental metabolomics: Analytical strategies. Mar. Chem. 177: 374-387. doi:10.1016/j.marchem.2015.06.029

Kiene, R. P., L. J. Linn, and J. a. Bruton. 2000. New and important roles for DMSP in marine microbial communities. J. Sea Res. 43: 209-224. doi:10.1016/S13851101(00)00023-X

Kirchman, D. L. 2008. Introduction and overview, p. 1-26. In D.L. Kirchman [ed.], Microbial Ecology of the Oceans. Wiley-Blackwell.

Kruskopf, M., and K. J. Flynn. 2006. Chlorophyll content and fluorescence responses cannot be used to gauge reliably phytoplankton biomass, nutrient status or growth rate. New Phytol. 169: 525-536. doi:10.1111/j.1469-8137.2005.01601.x

Kujawinski, E. B. 2011. The impact of microbial metabolism on marine dissolved organic matter. Ann. Rev. Mar. Sci. 3: 567-99. doi:10.1146/annurev-marine120308-081003

Kujawinski, E. B., K. Longnecker, H. Alexander, S. T. Dyhrman, C. L. Fiore, S. T. Haley, and W. M. Johnson. 2017. Phosphorus availability regulates intracellular nucleotides in marine eukaryotic phytoplankton. Limnol. Oceanogr. Lett. 2: 119129. doi:10.1002/lol2.10043

Kujawinski, E. B., R. Del Vecchio, N. V. Blough, G. C. Klein, and A. G. Marshall. 2004. Probing molecular-level transformations of dissolved organic matter: Insights on photochemical degradation and protozoan modification of DOM from electrospray ionization Fourier transform ion cyclotron resonance mass spectrometry. Mar. Chem. 92: 23-37. doi:10.1016/j.marchem.2004.06.038

Lesser, M. P. 2006. Oxidative stress in marine environments: Biochemistry and physiological ecology. Annu. Rev. Physiol. 68: 253-278. doi:10.1146/annurev.physiol.68.040104.110001

Li, W. K. W., and W. G. Harrison. 2001. Chlorophyll, bacteria and picophytoplankton in ecological provinces of the North Atlantic. Deep. Res. Part II Top. Stud. Oceanogr. 48: 2271-2293. doi:10.1016/S0967-0645(00)00180-6

Lomas, M. W., J. A. Bonachela, S. A. Levin, and A. C. Martiny. 2014. Impact of ocean phytoplankton diversity on phosphate uptake. Proc. Natl. Acad. Sci. U. S. A. 111: 17540-17545. doi:10.1073/pnas.1420760111

Longnecker, K., M. C. Kido Soule, and E. B. Kujawinski. 2015. Dissolved organic matter produced by Thalassiosira pseudonana. Mar. Chem. 168: 114-123. doi:10.1016/j.marchem.2014.11.003

McCarthy, M., J. Hedges, and R. Benner. 1996. Major biochemical composition of dissolved high molecular weight organic matter in seawater. Mar. Chem. 55: 281297. doi:10.1016/S0304-4203(96)00041-2

Melamud, E., L. Vastag, and J. D. Rabinowitz. 2010. Metabolomic analysis and visualization engine for LC-MS data. Anal. Chem. 82: 9818-9826. 
892

893

894

895

896

897

898

899

900

901

902

903

904

905

906

907

908

909

910

911

912

913

914

915

916

917

918

919

920

921

922

923

924

925

926

927

928

929

930

931

932

933

934

935

936

937

Mittenhuber, G. 2001. Phylogenetic analyses and comparative genomics of vitamin B6 (pyridoxine) and pyridoxal phosphate biosynthesis pathways. J. Mol. Microbiol. Biotechnol. 3: 1-20.

Mopper, K., and P. Lindroth. 1982. Diel and depth variations in dissolved free amino acids and ammonium in the Baltic Sea determined by shipboard HPLC analysis. Limnol. Oceanogr. 27: 336-347. doi:10.4319/1o.1982.27.2.0336

Moran, M. A., E. B. Kujawinski, A. Stubbins, and others. 2016. Deciphering ocean carbon in a changing world. Proc. Natl. Acad. Sci. U. S. A. 113: 3143-3151. doi:10.1073/pnas.1514645113

Noble, R. T., and J. A. Fuhrman. 1998. Use of SYBR Green I for rapid epifluorescence counts of marine viruses and bacteria. Aquat. Microb. Ecol. 14: 113-118. doi:10.3354/ame014113

Parsek, M. R., D. L. Val, B. L. Hanzelka, J. E. Cronan, and E. P. Greenberg. 1999. Acyl homoserine-lactone quorum-sensing signal generation. Proc. Natl. Acad. Sci. U. S. A. 96: 4360-5. doi:10.1073/pnas.96.8.4360

Paul, C., M. A. Mausz, and G. Pohnert. 2012. A co-culturing/metabolomics approach to investigate chemically mediated interactions of planktonic organisms reveals influence of bacteria on diatom metabolism. Metabolomics 9: 349-359. doi: 10.1007/s11306-012-0453-1

Pohnert, G. 2000. Wound-activated chemical defense in a unicelular planktonic algae. Angew. Chemie Int. Ed. 30: 4352-4354.

R Core Team. 2015. R: A language and environment for statistical computing.

Rabinowitz, J. D., and E. Kimball. 2007. Acidic acetonitrile for cellular metabolome extraction from Escherichia coli. Anal. Chem. 79: 6167-6173.

Raina, A., K. Tuomi, and R. L. Pajula. 1982. Inhibition of the synthesis of polyamines and macromolecules by 5 '-methylthioadenosine and 5 '-alkylthiotubercidins in BHK21 cells. Biochem. J. 204: 697-703.

Rajamani, S., W. D. Bauer, J. B. Robinson, and others. 2008. The vitamin riboflavin and its derivative lumichrome activate the LasR bacterial quorum-sensing receptor. Mol. plant-microbe Interact. 21: 1184-92. doi:10.1094/MPMI-21-9-1184

Rich, J., M. Gosselin, E. Sherr, B. Sherr, and D. L. Kirchman. 1997. High bacterial production, uptake and concentrations of dissolved organic matter in the Central Arctic Ocean. Deep. Res. Part II Top. Stud. Oceanogr. 44: 1645-1663. doi:10.1016/S0967-0645(97)00058-1

Sañudo-Wilhelmy, S. A., L. S. Cutter, R. Durazo, and others. 2012. Multiple B-vitamin depletion in large areas of the coastal ocean. Proc. Natl. Acad. Sci. U. S. A. 109: 14041-5. doi:10.1073/pnas. 1208755109

Schlitzer, R. 2016. Ocean Data View.

Seif, Y., K. Sonal, Y. Hefner, A. Anand, and L. Yang. 2020. Metabolic and genetic basis for auxotrophies in Gram-negative species. Proc. Natl. Acad. Sci. doi:10.1073/pnas.1910499117

Seyedsayamdost, M. R., R. J. Case, R. Kolter, and J. Clardy. 2011. The Jekyll-and-Hyde chemistry of Phaeobacter gallaeciensis. Nat. Chem. 3: 331-335. doi:10.1038/nchem.1002

Søndergaard, M., P. J. le B. Williams, G. Cauvet, B. Riemann, C. Robinson, S. Terzic, E. M. S. Woodward, and J. Worm. 2000. Net accumulation and flux of dissolved 
organic carbon and dissolved organic nitrogen in marine plankton communities. Limnol. Oceanogr. 45: 1097-1111.

941

942

943

944

945

946

947

948

949

950

951

952

953

954

955

956

957

958

959

960

961

962

963

964

965

966

Storey, J. D. 2002. A direct approach to false discovery rates. J. R. Stat. Soc. B 64: 479498. doi:10.1073/pnas.81.19.5921

Storey, J. D. 2010. False Discovery Rates Multiple Hypothesis Testing. 1-7.

Storey, J. D., and R. Tibshirani. 2003. Statistical significance for genomewide studies. Proc. Natl. Acad. Sci. U. S. A. 100: 9440-9445. doi:10.1073/pnas.1530509100

Takasu, H., and T. Nagata. 2015. High proline content of bacteria-sized particles in the Western North Pacific and its potential as a new biogeochemical indicator of organic matter diagenesis. Front. Mar. Sci. 2: 110. doi:10.3389/fmars.2015.00110

Thompson, P. A., M. X. Guo, P. J. Harrison, and J. N. C. Whyte. 1992. Effects of variation in temperature. II. On the fatty-acid composition of eight species of marine phytoplankton. J. Phycol. 28: 488-497. doi:10.1111/j.0022-3646.1992.00488.x

Winkler, W. C., and R. R. Breaker. 2005. Regulation of Bacterial Gene Expression By Riboswitches. Annu. Rev. Microbiol. 59: 487-517. doi:doi:10.1146/annurev.micro.59.030804.121336

Yancey, P. H., W. R. Blake, and J. Conley. 2002. Unusual organic osmolytes in deep-sea animals: Adaptations to hydrostatic pressure and other perturbants. Comp. Biochem. Physiol. Part A 133: 667-676. doi:10.1016/S1095-6433(02)00182-4

Yancey, P. H., M. E. Clark, S. C. Hand, R. D. Bowlus, and G. N. Somero. 1982. Classes of intracellular osmolyte systems and their distributions living with water stress: Evolution of osmolyte systems. Science (80-. ). 217: 1214-1222. doi:10.1126/science.7112124

Yentsch, C. S., and D. W. Menzel. 1963. A method for the determination of phytoplankton chlorophyll and phaeophytin by fluorescence. Deep Sea Res. Oceanogr. Abstr. 10: 221-231. doi:10.1016/0011-7471(63)90358-9

Zhang, S., X. Yang, M. Sun, F. Sun, S. Deng, and H. Dong. 2009. Riboflavin-induced priming for pathogen defense in Arabidopsis thaliana. J. Integr. Plant Biol. 51: 167174. doi:10.1111/j.1744-7909.2008.00763.x

Zubkov, M. V., M. A. Sleigh, G. A. Tarran, P. H. Burkill, and R. J. G. Leakey. 1998. Picoplanktonic community structure on an Atlantic transect from $50^{\circ} \mathrm{N}$ to $50^{\circ} \mathrm{S}$.

969

970 Deep. Res. Part I Oceanogr. Res. Pap. 45: 1339-1355. doi:10.1016/S0967-

971 
972 Table 1. Range of particulate concentrations of each metabolite and prevalence in

973 samples. Minimum concentration is the lowest value in a sample where the metabolite

974 was detected. "Picomoles of particulate metabolite per liter filtered. Values with a " $<$ "

975 symbol indicate the detection limit of the metabolite as the metabolite was not detected in

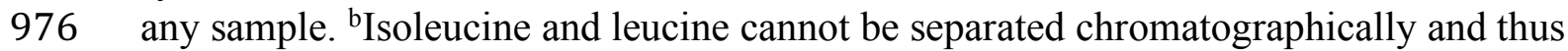

977 their combined concentrations are reported as (iso)leucine.

\begin{tabular}{|c|c|c|c|c|c|}
\hline Compound & Abbreviation & $\begin{array}{r}\operatorname{Min}^{\mathrm{a}} 1 \\
\quad>0\end{array}$ & $\begin{array}{l}\text { Max } \\
{ }^{\mathbf{a}} \mathbf{p M}\end{array}$ & $\begin{array}{c}\text { \# of samples } \\
<200 m \\
(n=34)\end{array}$ & $\begin{array}{c}\text { \# of samples } \\
>200 m \\
(n=46)\end{array}$ \\
\hline 2,3-Dihydroxybenzoic acid & 2,3-DHBA & 1.6 & 1.6 & 1 & 0 \\
\hline 3-Mercaptopropionate & & $<12$ & $<12$ & 0 & 0 \\
\hline 4-Aminobenzoic acid & PABA & $<0.6$ & $<0.6$ & 0 & 0 \\
\hline 4-Hydroxybenzoic acid & 4-HBA & 0.9 & 4.4 & 2 & 2 \\
\hline 5-Methylthioadenosine & MTA & 0.1 & 1.0 & 29 & 2 \\
\hline Adenine & & 0.6 & 22 & 11 & 21 \\
\hline Adenosine & & 0.09 & 85 & 29 & 17 \\
\hline $\begin{array}{l}\text { Adenosine } 5 '- \\
\text { monophosphate }\end{array}$ & AMP & 0.07 & 98 & 30 & 25 \\
\hline Arginine & & 2.4 & 46 & 9 & 22 \\
\hline Biotin (vitamin $\mathrm{B}_{7}$ ) & & 0.03 & 1.0 & 4 & 5 \\
\hline Caffeine & & 0.02 & 4.2 & 12 & 34 \\
\hline Cytosine & & $<2.2$ & $<2.2$ & 0 & 0 \\
\hline Desthiobiotin & & 0.3 & 0.3 & 1 & 0 \\
\hline Dimethylsulfoniopropionate & DMSP & 13 & 6200 & 34 & 8 \\
\hline Folic acid & & 0.2 & 0.8 & 2 & 2 \\
\hline Glutamic acid & & 61 & 9800 & 28 & 7 \\
\hline Guanine & & 1.3 & 1000 & 34 & 43 \\
\hline Glycine betaine & & 8.1 & 1300 & 33 & 7 \\
\hline Indole 3 -acetic acid & & 0.2 & 0.2 & 1 & 0 \\
\hline Inosine 5'-monophosphate & IMP & 0.9 & 0.9 & 1 & 0 \\
\hline Inosine & & 0.04 & 18 & 27 & 14 \\
\hline (Iso)leucine ${ }^{b}$ & & 0.3 & 41 & 22 & 20 \\
\hline Methionine & & 1.5 & 39 & 4 & 2 \\
\hline$N$-acetyl glucosamine & & $<9$ & $<9$ & 0 & 0 \\
\hline $\begin{array}{l}\text { Pantothenic acid (vitamin } \\
\text { B5) }_{5}\end{array}$ & & $<6.7$ & $<6.7$ & 0 & 0 \\
\hline Phenylalanine & & 0.05 & 58 & 34 & 43 \\
\hline Proline & & 0.2 & 110 & 23 & 25 \\
\hline Pyridoxine (vitamin $\mathrm{B}_{6}$ ) & & 0.1 & 2 & 8 & 20 \\
\hline Riboflavin (vitamin $\mathrm{B}_{2}$ ) & & 0.003 & 0.7 & 13 & 1 \\
\hline Tryptophan & & 0.02 & 20 & 33 & 32 \\
\hline Uracil & & 7.4 & 400 & 8 & 5 \\
\hline Xanthine & & 0.2 & 29 & 21 & 5 \\
\hline
\end{tabular}


979 Table 2. Range of dissolved concentrations of each metabolite and prevalence in

980 samples. Minimum concentration is the lowest value in a sample where the metabolite

981 was detected. Values with a " $<$ " symbol indicate the detection limit of the metabolite as

982 the metabolite was not detected in any sample.

\begin{tabular}{|c|c|c|c|c|c|}
\hline Compound & Abbreviation & $\begin{array}{c}\text { Min } \\
(\mathbf{p M}) \\
(>0) \\
\end{array}$ & $\begin{array}{l}\text { Max } \\
(\mathbf{p M})\end{array}$ & $\begin{array}{c}\text { \# of samples } \\
<200 \mathrm{~m} \\
(\mathrm{n}=\mathbf{2 6}) \\
\end{array}$ & $\begin{array}{c}\text { \# of samples } \\
>200 \mathrm{~m} \\
(\mathrm{n}=\mathbf{2 8}) \\
\end{array}$ \\
\hline 2,3-Dihydroxybenzoic acid & 2,3-DHBA & 4.2 & 9.9 & 3 & 0 \\
\hline 3-Mercaptopropionic acid & & $<78$ & $<78$ & 0 & 0 \\
\hline 4-Aminobenzoic acid & PABA & 16 & 51 & 25 & 0 \\
\hline 4-Hydroxybenzoic acid & 4-HBA & 15 & 61 & 7 & 0 \\
\hline 5-Methylthioadenosine & MTA & 1.1 & 2.6 & 9 & 0 \\
\hline Adenosine & & $<123$ & $<123$ & 0 & 0 \\
\hline Biotin & & 3.5 & 26 & 6 & 2 \\
\hline Caffeine & & 2.6 & 8.7 & 12 & 4 \\
\hline Chitotriose & & 12 & 130 & 7 & 1 \\
\hline Cyanocobalamin & & $<0.8$ & $<0.8$ & 0 & 0 \\
\hline Desthiobiotin & & 27 & 27 & 1 & 0 \\
\hline Folic acid & & $<0.7$ & $<0.7$ & 0 & 0 \\
\hline Indole 3 -acetic acid & & 5.7 & 5.7 & 1 & 0 \\
\hline Inosine & & 16 & 29 & 2 & 0 \\
\hline (Iso)leucine & & 90 & 230 & 4 & 0 \\
\hline$N$-Acetylglutamic acid & & 220 & 600 & 1 & 1 \\
\hline $\begin{array}{l}\text { Nicotinamide adenine } \\
\text { dinucleotide }\end{array}$ & NAD & 56 & 56 & 1 & 0 \\
\hline Pantothenic acid & & 1.0 & 19 & 22 & 0 \\
\hline Phenylalanine & & 2.2 & 290 & 26 & 12 \\
\hline Pyridoxine & & $<236$ & $<236$ & 0 & 0 \\
\hline Riboflavin & & 0.7 & 12 & 10 & 7 \\
\hline $\begin{array}{l}S-\left(5^{\prime} \text {-Adenosyl }\right)-\mathrm{L}- \\
\text { homocysteine }\end{array}$ & & $<72$ & $<72$ & 0 & 0 \\
\hline Taurocholic acid & & $<5$ & $<5$ & 0 & 0 \\
\hline Thiamin & & 4000 & 4000 & 1 & 0 \\
\hline Thymidine & & $<123$ & $<123$ & 0 & 0 \\
\hline Tryptophan & & 20 & 190 & 18 & 1 \\
\hline
\end{tabular}

983 
a

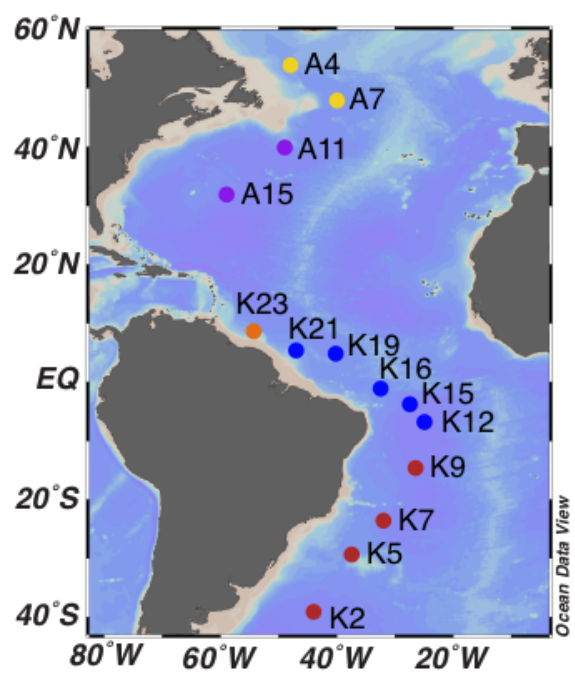

986

987

988

989

990

991

992

993

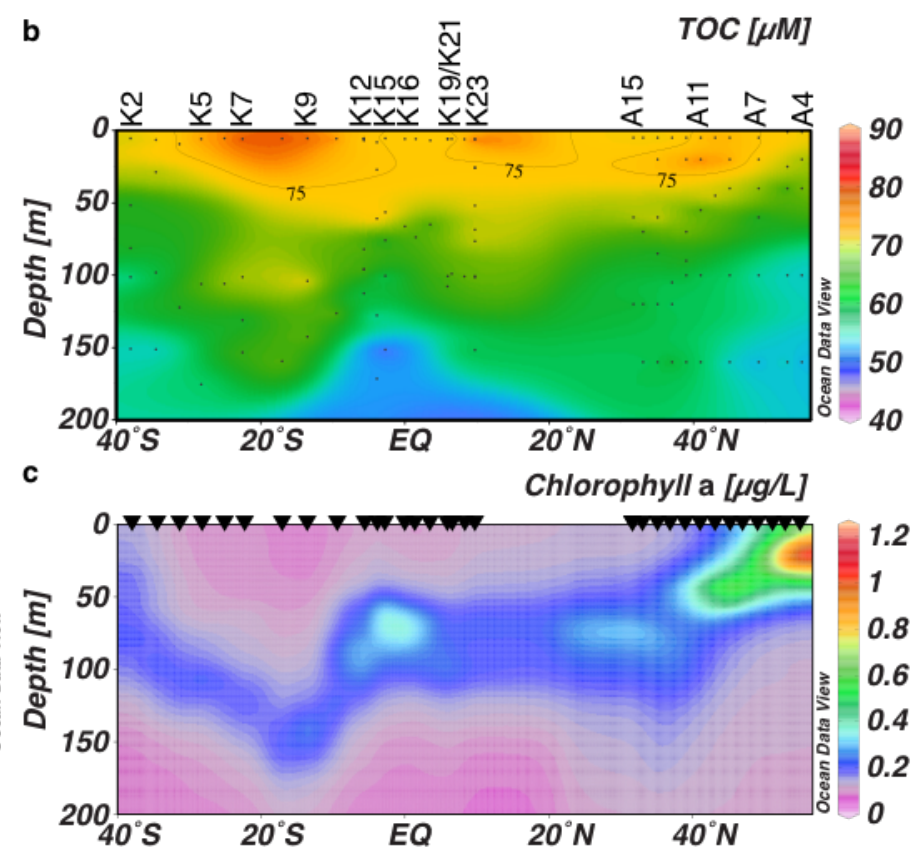

Figure 1. Transect stations and chemical parameters. (a) Stations sampled along a latitudinal transect in the western Atlantic Ocean. Dots colored by region: red, South Atlantic Gyre; blue, equatorial region; orange, Amazon plume; purple, North Atlantic Gyre; yellow, Labrador Sea. (b) The total organic carbon (TOC) concentration in the top $200 \mathrm{~m}$ along the transect. Black dots indicate sample locations. (c) Chlorophyll $a$ concentrations in the top $200 \mathrm{~m}$ along the transect. Triangles indicate locations of CTD casts where fluorescence was measured. 


\section{4}

a. Particulate guanine (pM)
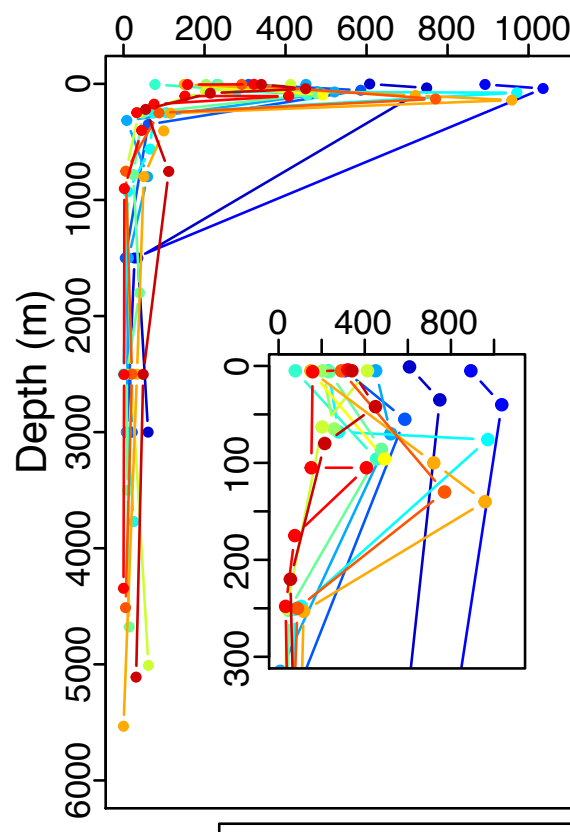

b.
Particulate guanine
(mole fraction)

Particulate guanine
(mole fraction)

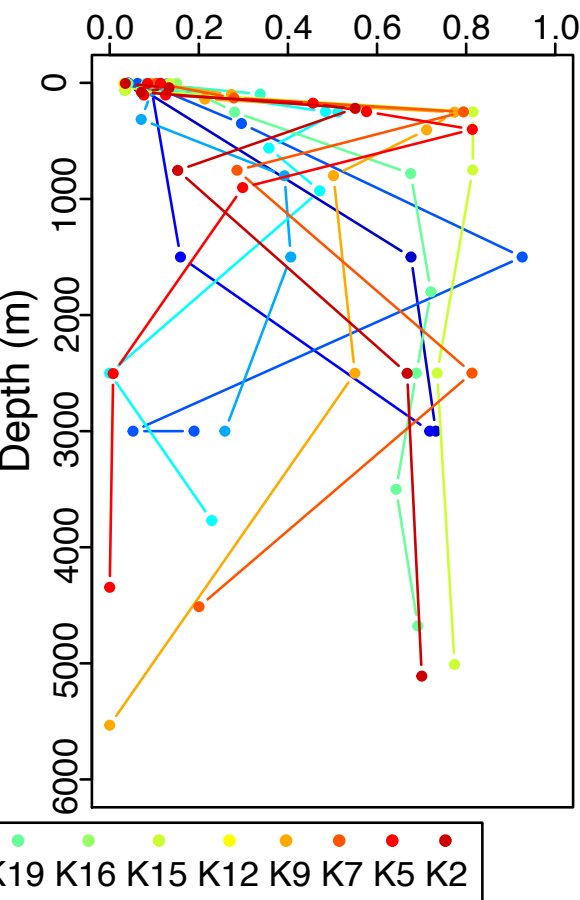

995 Figure 2. Particulate guanine abundance with depth. (a) Picomoles particulate guanine A4 A7 A11 A15 K23 K21 K19 K16 K15 K12 K9 K7 K5 K2 normalized to liter of seawater sampled, profiled by depth for each station. Cut-out shows the top $300 \mathrm{~m}$ of the water column in more detail. (b) Moles of guanine normalized to total moles targeted metabolites, profiled by depth for each station. Stations are indicated 1000 

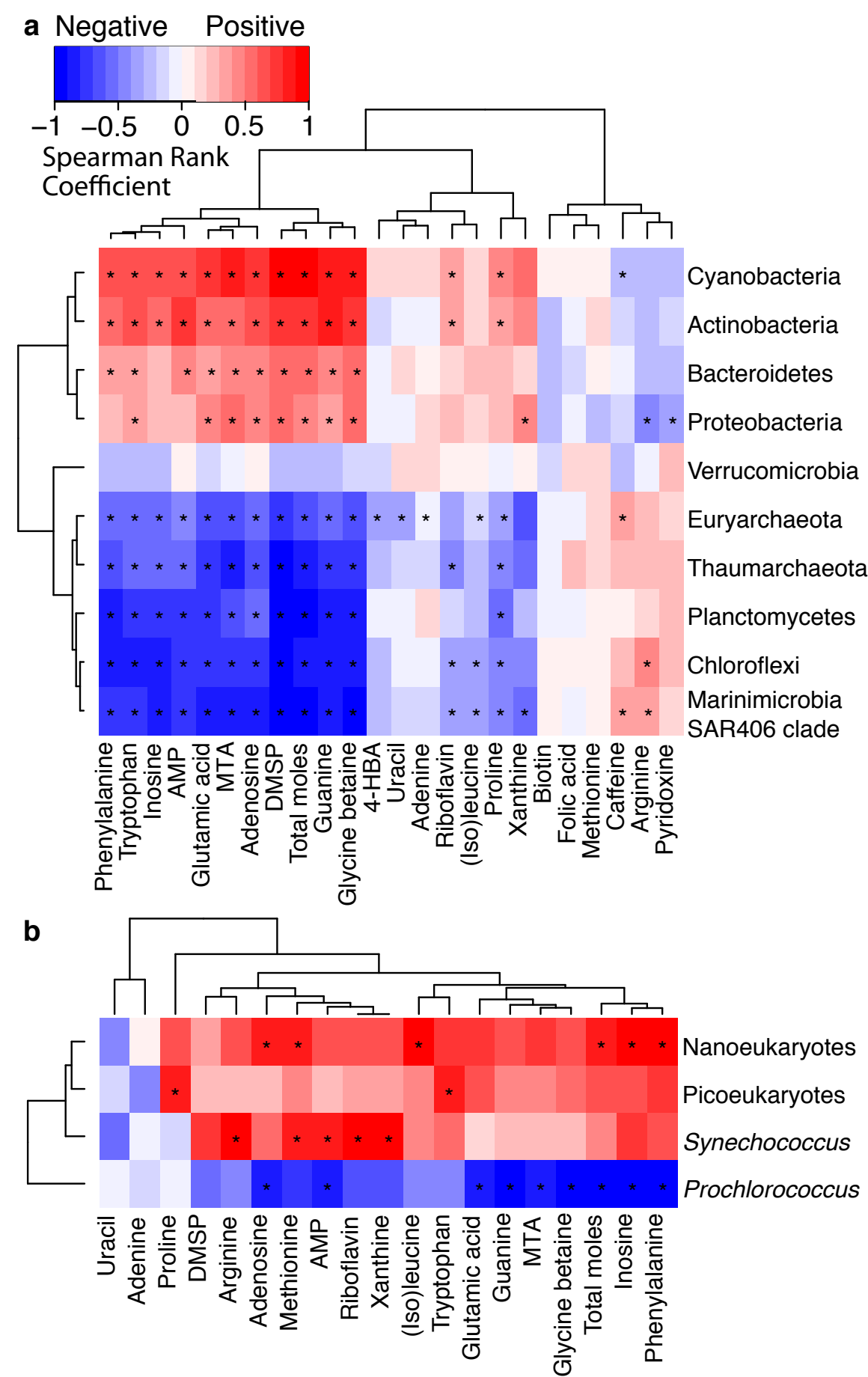

1002 Figure 3. Spearman rank correlation coefficients plotted as a heatmap with hierarchical 1003 clustering showing the relationship between particulate metabolites and abundance of 1004 microbial community members. Red indicates a positive correlation and blue indicates a negative correlation. * Indicates correlations with significant $p$-values. (a) Comparison of metabolites to phyla from KN210-04 samples $(p<0.05)$. (b) Comparison of AE1319 metabolite samples from the surface and DCM to groups identified with flow cytometry $1008(p<0.06$, see text $)$. 


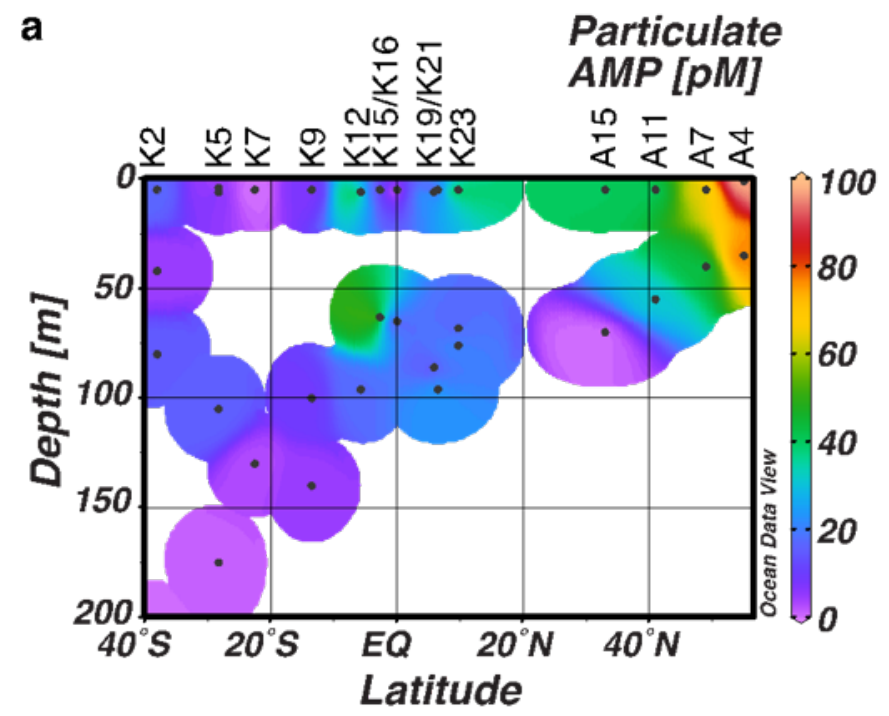

b

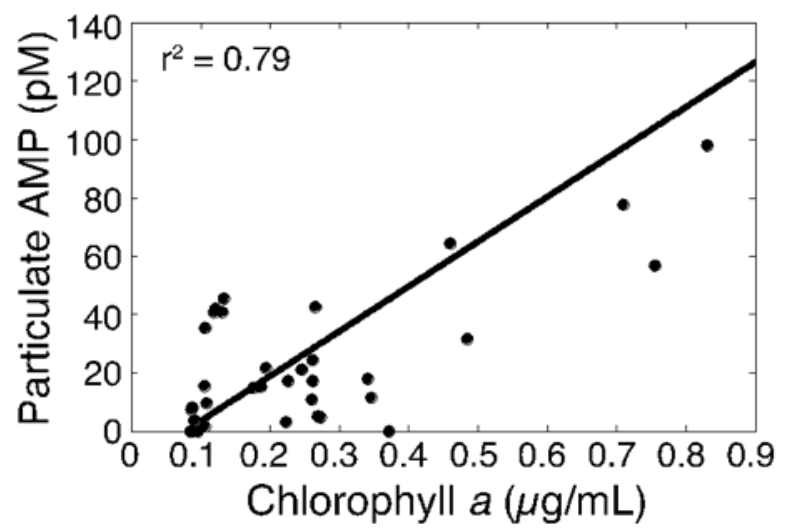

1010 Figure 4. Particulate adenosine 5'-monophosphate (AMP) abundance with depth (a) and 1011 relative to chlorophyll $a$ concentrations (b). (a) AMP abundance (pM) above 200 m. (b) 1012 Linear regression of chlorophyll $a$ versus AMP, with $\mathrm{r}^{2}$ value 0.79 and $p<0.001$ (slope $=$ 1013 154, y-intercept $=-12$ ).

1014

1015 
1016

1017

1018

1019

a

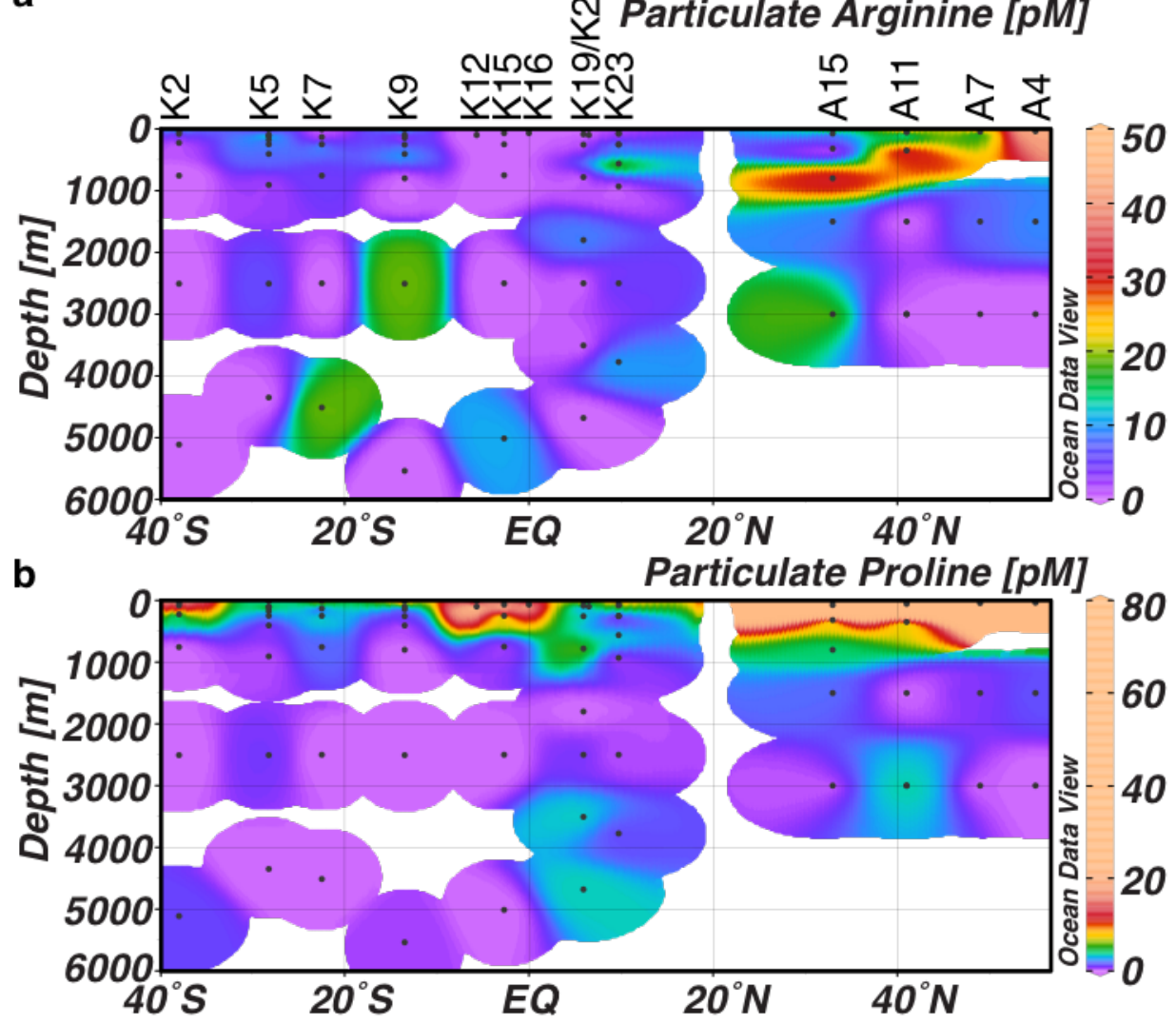

Figure 5. Distributions of particulate (a) arginine and (b) proline measured at depth. 


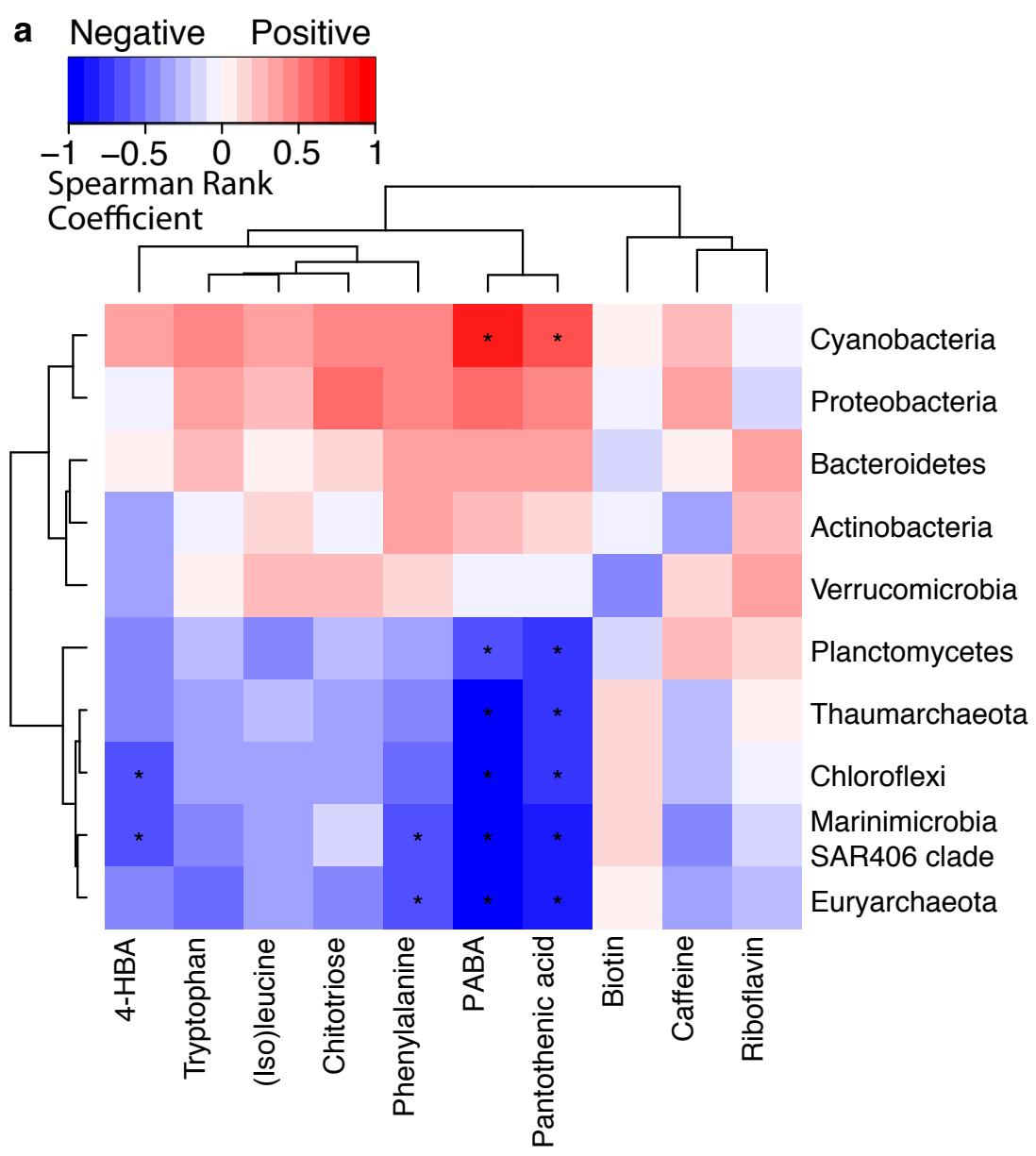

b
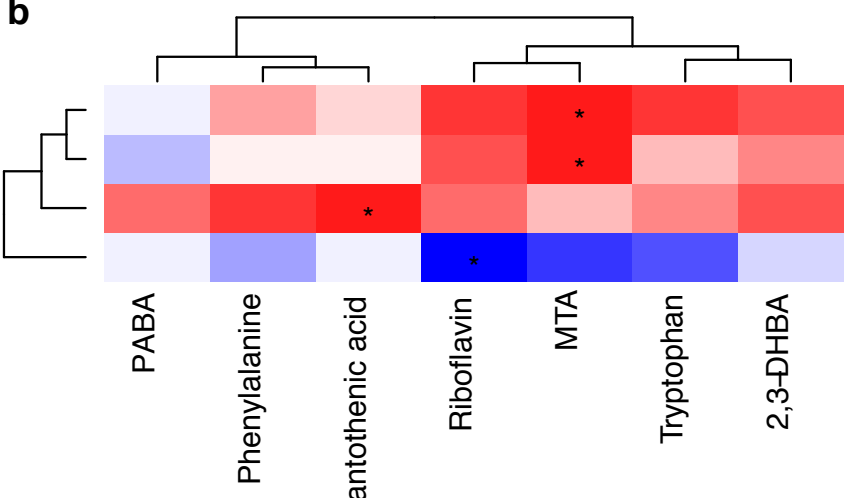

Nanoeukaryotes

Picoeukaryotes

Synechococcus

Prochlorococcus

Figure 6. Spearman rank correlation coefficients plotted as a heatmap with hierarchical clustering showing the relationship between dissolved metabolites and abundance of microbial community members. Red indicates a positive correlation and blue indicates a negative correlation. * Indicates correlations with significant $p$-values. We include only samples collected in the upper $250 \mathrm{~m}$ as there were too few metabolites measured in the deeper samples (Table 2). (a) Comparison of metabolites to phyla from KN210-04 samples from $250 \mathrm{~m}$ and above $(p<0.05)$. (b) Comparison of AE1319 metabolite samples from the surface and DCM to groups identified with flow cytometry $(p<0.35)$. 


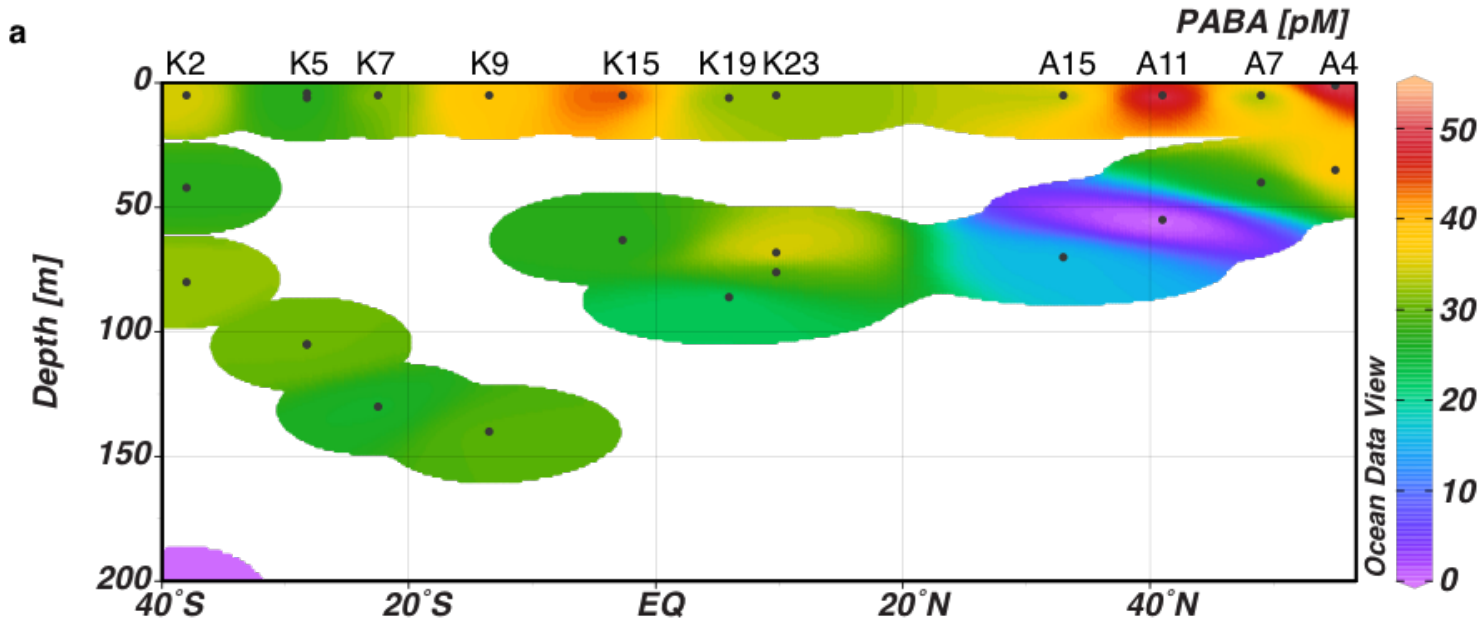

b

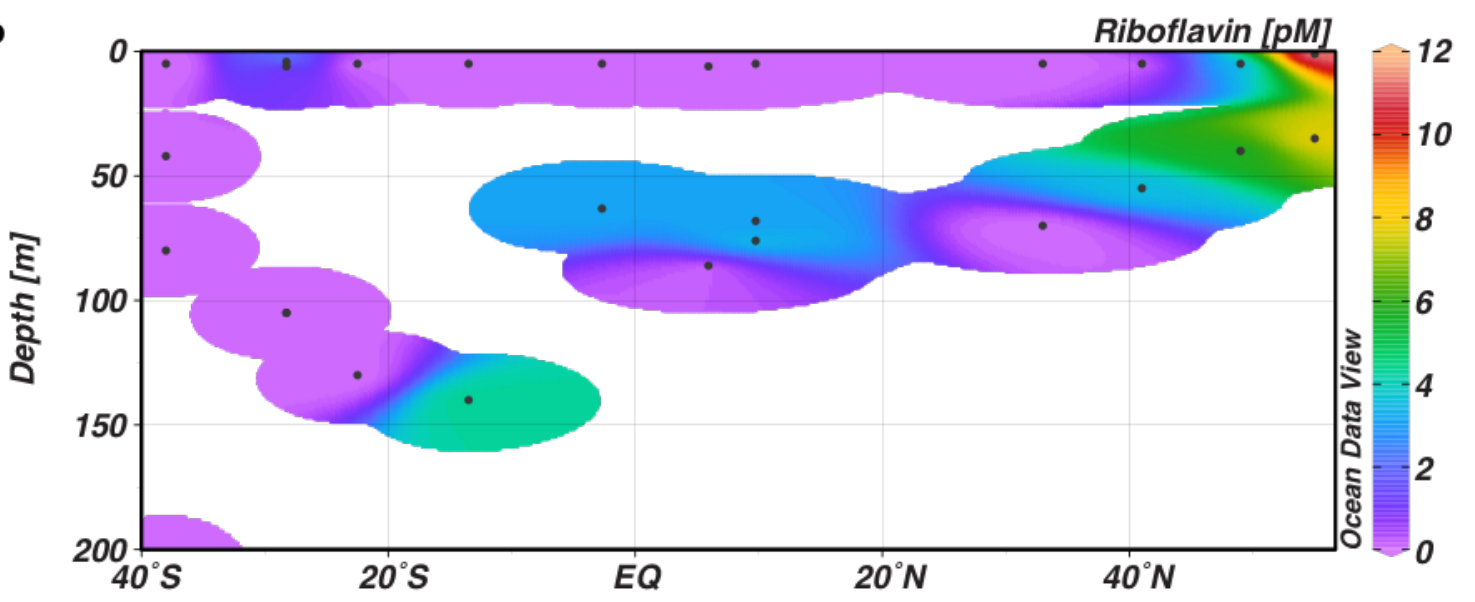

1030 Figure 7. Concentrations of (a) dissolved 4-aminobenzoic acid (PABA) and (b) 1031 riboflavin $(\mathrm{pM})$ in the top $200 \mathrm{~m}$ of the water column. 


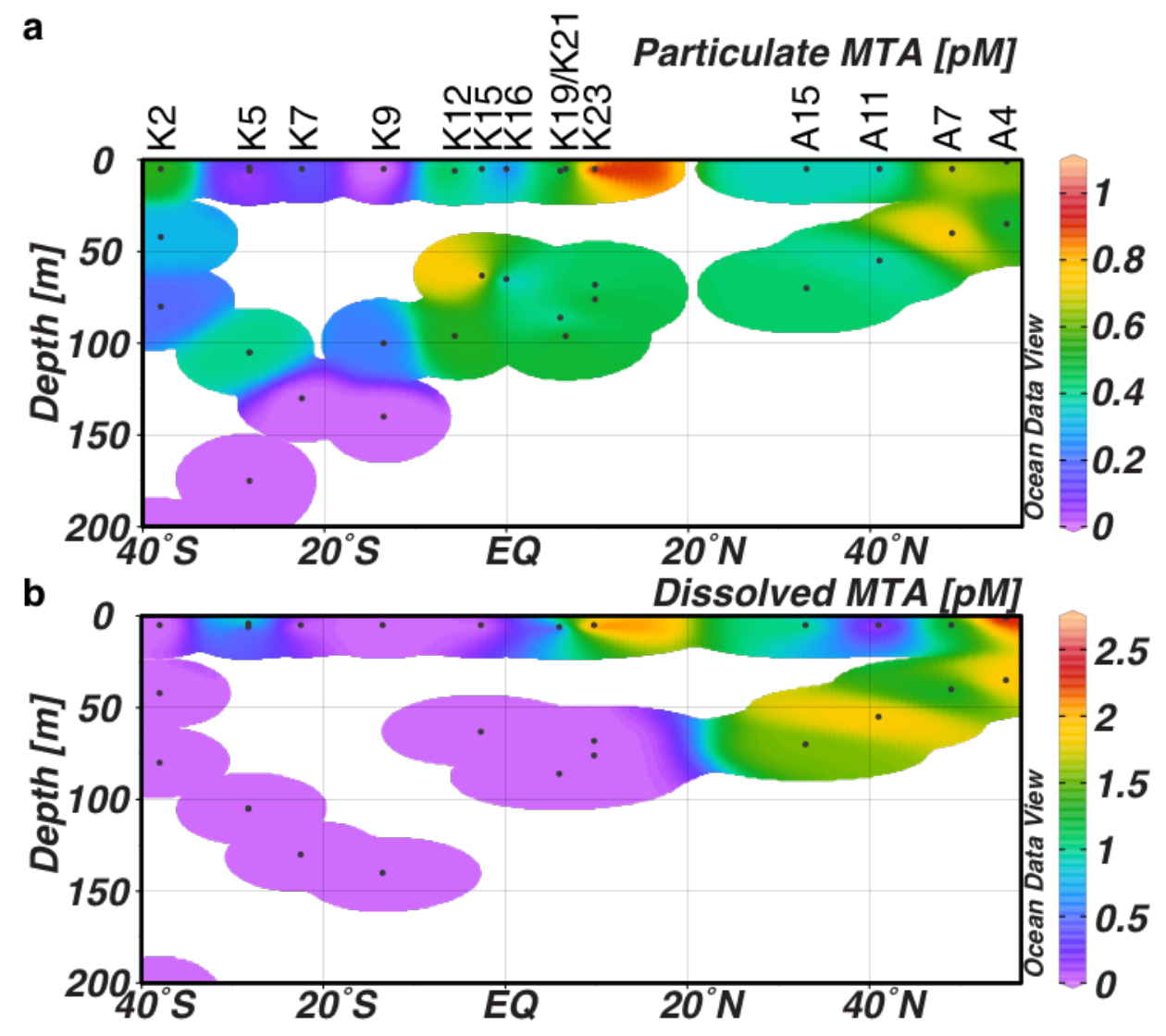

1034 Figure 8. (a) Particulate 5-methylthioadenosine (MTA) normalized to the total volume 1035 filtered, and (b) pM dissolved MTA across the transect. 